\title{
Dual-Channel Green Supply Chain Decision-Making and Coordination considering CSR and Consumer Green Preferences
}

\author{
Xiaochun Chen $\left(\mathbb{D},{ }^{1}\right.$ Rui Zhang $\mathbb{D}^{2},{ }^{2}$ and Bo $\operatorname{Lv} \mathbb{D}^{1}$ \\ ${ }^{1}$ Business School, Beijing Wuzi University, Beijing 101125, China \\ ${ }^{2}$ Business School, Beijing Normal University, Beijing 100875, China \\ Correspondence should be addressed to Rui Zhang; 327640307@qq.com and Bo Lv; lvbo732021@163.com
}

Received 15 June 2021; Revised 6 September 2021; Accepted 25 October 2021; Published 23 November 2021

Academic Editor: Juan L. G. Guirao

Copyright ( $) 2021$ Xiaochun Chen et al. This is an open access article distributed under the Creative Commons Attribution License, which permits unrestricted use, distribution, and reproduction in any medium, provided the original work is properly cited.

\begin{abstract}
With the rapid development of the Internet and changes in consumer buying habits, many manufacturers are increasingly relying on online channels to sell their products as opposed to traditional retail channels. In this study, we innovatively investigate the impact of corporate social responsibility (CSR) and consumer green preferences (CGP) on supply chain performance and product green level in the dual-channel green supply chain (DCGSC). Specifically, four models of DCGSC (centralized, independent CSR, cooperative CSR, and collaboration contract) are investigated. Next, we use game theory to investigate the optimal product green level, online and offline selling prices, social welfare, profits of supply chain enterprises, and the whole supply chain under the four models. We give numerical examples to demonstrate the effectiveness and viability of the four models. We find several interesting conclusions. First, increasing the attention to both CSR and CGP by supply chain enterprises is conducive to stimulating innovation and improving product green level. Second, when supply chain enterprises actively execute their CSR, they can reasonably control online and offline selling prices and increase consumer surplus and the profits of whole supply chain and social welfare are increased. Third, it is beneficial to increase the value of supply chain enterprises to enhance CSR within a certain threshold, but when CSR is higher than the threshold, the profitability of supply chain enterprises is weakened. Finally, collaboration contracts are capable of coordinating DCGSC and guaranteeing the profitability of supply chain enterprises.
\end{abstract}

\section{Introduction}

The problems of environmental pollution and resource scarcity have become increasingly prominent. Therefore, there is an urgent need for the supply chain together with other industries to fully execute their environmental protection responsibilities. This will require transformation and upgrading of the economic development models of enterprises to low carbon, environmental protection, and green innovation. Green innovation is the core driving force for the development of the green industry $[1,2]$. It is also crucial to promoting the development of a high-quality green economy. So, how can supply chain enterprises be incentivized to enhance their level of green innovation? Green innovation is important to promote corporate environmental comanagement and sustainable development is crucial for a green supply chain [3]. The ongoing environmental degradation would worsen if the adoption of green technology is not expedited [4, 5]. In 2018, an Environmental Protection Tax was introduced in China and environmental supervision was strengthened with more severe punishments for breaking environmental laws [6]. The support of green consumers and the construction of green supply chains are crucial for environmental protection. To develop a green circular economy and influence consumers toward green preferences, enterprises have invested in the research and development of healthy, energyefficient, and environmentally friendly green technologies. For example, the GREE Group is actively promoting research and development of environmentally friendly and energy-efficient technologies to increase its competitiveness and image, and BYD has formulated responsibility requirements for its supply chain partners to reduce the direct impact of its business activities on the environment. Today, 
an increasing number of consumers are buying green products even if it means paying higher prices, and their motivation is to protect the environment [7]. This is encouraging many manufacturers and retailers to produce or sell green products. Furthermore, with the rapid development of the Internet, many manufacturers are increasingly using dual channels to sell their products, that is, the traditional retail channel and online direct sales [8]. While CSR plays a key role in social and environmental research $[9,10]$, CSR in the DCGSC studies is lacking and is highly underresearched area. Therefore, further study is needed to investigate and understand the critical role of CSR in the DCGSC. Therefore, this study differs slightly from other research studies; we seek to answer the following questions: What impact do CSR and CGP have on green innovation and the efficiency of the dual-channel green supply chain (DCGSC)? How can supply chain enterprises be incentivized to enhance their level of green innovation to achieve efficient synergy of economic, social, and environmental benefits? Which decision-making model has the highest level of green innovation and supply chain efficiency and the greatest social welfare? How can collaborative mechanisms be designed to make supply chain enterprises more active in executing their CSR responsibilities and improve the efficiency of the DCGSC? What are the important and realistic issues facing supply chain enterprises?

A significant amount of literature is related to the topic of this study. Specifically, this study is related to the literature on CSR, CGP, and channel coordination.

1.1. Corporate Social Responsibility. CSR practices have a significant influence on environmentally sustainable development [11]. Scholars around the world are increasingly interested in CSR $[12,13]$ and ways of incorporating CSR into supply chain decision-making. In practice, a higher innovation performance is associated with an increase in green CSR [14]. Moreover, as the global concern for green sustainable development increases, it extends to the impact of CSR on green innovation, for example, the report by Leng et al. [15] which elucidated that CSR information disclosure can significantly ease financing constraints, thereby positively affecting the sustainability of corporate innovation. In practice, CSR not only positively affects green performance but also effectively enhances the ability to achieve green performance [16, 17]. Shahzad et al. [18] examined how CSR affects corporate sustainability performance. Li et al. [19] found that the effect of CSR on innovation performance assumes an inverted U-shaped trend; that is, CSR can effectively promote corporate innovation performance within a certain critical point, but it will hinder innovation performance after the critical point is exceeded. Mehralian et al. [20] elucidated that CSR is not directly related to organizational performance. However, Panda et al. [21] argued that CSR is inversely proportional to the net profit of the enterprise and directly proportional to total profit, and CSR cannot achieve shareholder value and stakeholder value at the same time. Gang et al. [22] argued that increasing the level of CSR increases product demand and economic profitability for stakeholders but reduces economic returns for suppliers. In addition, the subjects of social responsibility that scholars pay attention to are not the same. Mainly from the perspective of the manufacturer's fulfillment of CSR [23], retailers fulfilling their CSR [24], and the manufacturers and retailers being individually concerned about CSR [25], it can be seen that the literature presents mixed findings and mostly focuses on the implementation of CSR by individual enterprises of the supply chain. Therefore, sustainable supply chain management requires a coordinated effort from all parties to achieve the sustainability objectives [26, 27]. It is not enough for enterprises to focus only on their own CSR, it is the joint fulfillment of CSR by supply chain enterprises that is favorable to maintain environmental sustainability [28]. Our study differs from previous studies in that we not only focus on the execution of CSR by manufacturers but also focus on the impact of CSR on the decision-making in the DCGSC from the perspective of manufacturers and retailers performing CSR together.

1.2. Consumer Green Preferences. As environmental problems continue to arise, the necessity of environmental protection is addressed by the increasing consumer preference for green products. An increasing number of scholars have begun to study CGPs. Simultaneously achieving economic and environmental goals has become an important issue in the process of green sustainable development [29]. Papadopoulos et al. [30] argued that consumers are increasingly getting concerned about environmental changes and have assumed behaviors that have made producers change their production. Borin et al. [31] found that purchase intentions for green products are significantly higher than those of nongreen products. Interestingly, consumers prefer to pay more for low-carbon, energy-saving, and eco-friendly products. These actions have led to the development of the green industry [32]. Suki [33] considered producers to place more emphasis on the social value of their products to increase environmental awareness among consumers and further encouraged the production of green goods that will be readily liked by consumers. Owing to the limited number of people who are willing to pay for green products, it is necessary to make all green goods affordable. This can be achieved by adopting green technologies to reduce the prices of the products [34]. Consequently, how can the adoption of green technology be accelerated? Researchers have put forward suggestions to increase the adoption of green technology. Wang et al. [35] elaborated that CGP significantly influences the product green level. Yu et al. [36] reported that an increase in consumer environmental awareness will incentivize manufacturers to produce more green products with higher green levels, but this does not necessarily lead to higher profits for the manufacturers. As can be seen, the above literature only considers the effects of consumer behavior on green products and green production. Little literature has investigated a combination of green preference and DCSC and their impact on social welfare. This is the research gap we intend to fill. 
1.3. Channel Coordination and Green Supply Chain. Previous studies have extensively investigated competition and pricing strategies for DCSC. Using the two-stage optimization technique and the Stackelberg game, Hua et al. [37] derived the optimal decisions on retail services and prices and the optimal decisions of delivery lead time and prices in centralized and decentralized DCSCs, respectively. The development of dual channels not only increases the competitive advantage of the manufacturer but also brings channel conflicts which in turn may cause problems between the manufacturer and the retailer [38]. A reliable cooperation arrangement between manufacturers and retailers is essential for the development of a robust green supply chain [39]. Some studies have investigated coordination strategies that are used to eliminate channel conflicts, and we review some of them here. Zhang and Liu [40] explored the coordination issue in different channel structures. Ranjan et al. [41] applied the Stackelberg game-theoretic approach to analyze the decentralized model, and the channel coordination is achieved through the surplus profit-sharing mechanism to obtain a win-win situation for each enterprise of the supply chain. However, none of these studies have investigated a green supply chain. Van et al. [42] suggested that green supply chains should be established to achieve both economic growth and environmental protection. Basiri and Heydari [43] studied the impact of consumer environmental awareness and the quality of green products on channel coordination for a two-stage green supply chain. Li et al. [44] argued that a low-carbon supply chain is particularly suited for the revenue-sharing contract. Besides, the cost-sharing contract is very prevalent in the green supply chain. Ghosh et al. [45] studied how product green level, price, and profits are influenced by cost-sharing contracts within the supply chain through a game-theoretic approach. Dai et al. [46] investigated how cost sharing is more beneficial to all members in a chain as opposed to noncooperativeness. Pu et al. [47] proposed and analyzed a costsharing contract that coordinated a decentralized DCSC to achieve beneficial outcomes for both parties. In summary, a significant amount of research has been conducted in the area of dual-channel coordination. Based on this, this paper designs CSR cost-sharing, revenue-sharing, and franchise combination contract to coordinate the dual-channel supply chain.

In summary, the existing literature has been separately focused on CSR, CGP, and channel coordination. There is little literature on the impact of CSR and CGP on the pricing and coordination decisions of the DCGSC, especially when both are simultaneously present in the system. This is the major motivation for this study. Both CSR and CGP act as key factors influencing the cooperative behavior of green supply chain enterprises. However, few studies have brought the two important issues together to systematically examine their impact on economic benefits and the social environment. Therefore, to fill the research gap, we analyzed the impact of CSR and CGP on innovation decisions in the DCGSC from the perspectives of economic and social benefits and constructed four decision-making models, centralized CSR decision-making, independent CSR decision-making, shared CSR decision-making, and CSR cost-sharing, revenue-sharing, and franchising combined contract. The contributions of this work are as follows: (1) Both CSR and CGP are key endogenous factors influencing consumer behavior and CSR affecting reputation acts as a concern for consumer surplus. (2) We explore the impact of CGP and CSR on product green level, online and offline selling prices, profits of enterprises in a supply chain, and social welfare based on the equilibrium results of four different decisions. (3) Among the four decision models, we identify the one that is most beneficial in supplying members and consumers in terms of economic and social benefits. (4) We construct a cost-sharing and franchise fee combination contract to coordinate and optimize the DCGSC. The research results provide strategies and references for enterprises to actively practice CSR and green activities.

This paper is organized as follows: In Section 2, we construct four decision-making models for the DCGSC. In Section 3, we discuss and compare the optimal product green level under the four models and equilibrium of the heterogeneous supply chain strategies. A numerical simulation is discussed in Section 4. In Section 5, we discuss the conclusions, research limitations, and suggestions for future research. Proofs are provided in Appendix A.

\section{Assumptions and Models}

\subsection{Problem Description and Notations}

Assumption 1. We assume that the DCGSC consists of one manufacturer acting as the leader and one retailer acting as the follower.

Assumption 2. In this paper, we consider a manufacturer that produces a single product at a unit cost $\mathrm{cm}$ and distributes it through an online direct channel at a price pd and through an offline retail channel at a wholesale price $w$. The retailer will resell the product through its channel at price pr. Customers may purchase the product either from the retail channel or from the online direct channel. To avoid a trivial case, it is assumed that $\mathrm{pd} \geq w$ and $\mathrm{pr} \geq w \geq \mathrm{cm}$.

Assumption 3. The manufacturer is responsible for the green cost, similar to the works of Shah et al. [45] and DavisSramek [48]; the manufacturer's investment cost to produce the green product is given by ce $=1 / 2 k e^{2}$, where $e$ represents the product green level and $k$ represents the cost coefficient of green level per unit.

Assumption 4. Linear demand functions have been adopted as in Li et al. [44], taking into account their preference for the environment; consumers are more inclined to products with a high green level. Therefore, after considering price, the demand functions of the respective channels can be obtained as follows.

The demand function of an offline channel is given by

$$
\mathrm{qr}=u-\mathrm{pr}+\alpha \mathrm{pd}+\lambda e .
$$



by

The demand function of an online direct channel is given

$$
\mathrm{qd}=u-\mathrm{pd}+\alpha \mathrm{pr}+\lambda e .
$$

Let $\mathrm{qr}$ and qd denote the consumer demands from the retail channel and direct channel, respectively. The parameter represents the initial market potential, $\lambda$ shows consumer sensitivity to the green preference, and $0 \leq \lambda \leq 1$ shows that the self-price demand elasticity of each channel is 1. The parameters measure the cross-price sensitivity. From observation, the self-price demand elasticity of each channel is more effective than the cross-price elasticity of demand; that is, $0<\alpha<1$.

Assumption 5. Being active in CSR effectively enhances the corporate reputation and brand image [49] and effectively increases consumer loyalty and trust in the brand [50]. Assuming that the consumers in the market prefer green products, supply chain enterprises not only pursue profit but also focus on CSR to gain a competitive advantage. Similar to the works of Panda et al. [51] and Sinayi et al. [52], we consider part of consumer surplus as a way to measure CSR. Let $\beta$ denote the degree of overall DCGSC paying attention to $\operatorname{CSR} \beta \in(0,1)$, let $c s$ denote the overall consumer surplus in the DCGSC, let $\beta$. cs denote CSR of the overall DCGSC, let $\beta \cdot \operatorname{csr}$ denote CSR of the offline channel, and let $\beta \cdot \operatorname{csd}$ denote CSR of the online channel. The offline and online consumer surplus can be calculated as follows:

$$
\operatorname{csd}=\int_{\mathrm{pd}}^{\mathrm{pd}_{\max }} \mathrm{qddpd}=\frac{(u-\mathrm{pd}+\alpha \mathrm{pr}+\lambda e)^{2}}{2} .
$$

Consumer surplus in offline channels is

$$
\operatorname{csr}=\int_{\mathrm{pr}}^{\mathrm{pr}_{\max }} \mathrm{qrdpr}=\frac{(u-\mathrm{pr}+\alpha \mathrm{pd}+\lambda e)^{2}}{2} .
$$

The overall consumer surplus in the DCGSC is

$$
\mathrm{cs}=\mathrm{csr}+\mathrm{csd} \text {. }
$$

The overall social welfare is the sum of consumer surplus and producer surplus:

$$
\mathrm{zs}^{j}=\mathrm{zm}^{j}+\mathrm{zr}^{j}+\mathrm{cs} .
$$

The basic notations are shown in Table 1.

In the next section, the profit functions of members of the DCGSC in centralized decision (Strategy C) and decentralized decision (Strategy M, Strategy MR, and Strategy MRD) are formulated.

2.2. Centralized Decision Model (C). There is a supply chain system consisting of a manufacturer and a retailer in the centralized decision model; we consider a single decisionmaker who sets the online selling price $\left(\mathrm{pd}^{C}\right)$, the offline selling price $\left(\mathrm{pr}^{C}\right)$, and the product green level $\left(e^{C}\right)$ by maximizing the total profit of the DCGSC. Thus, for centralized decision-making, the utility function of the DCGSC is as follows:

$$
\mathrm{St}^{c}=(\mathrm{pd}-\mathrm{cm}) \mathrm{qd}+(\mathrm{pr}-\mathrm{cm}) \mathrm{qr}-\mathrm{ce}+\beta \cdot \mathrm{cs} .
$$

The profit of the DCGSC is determined by

$$
z^{c}=\mathrm{St}^{c}-\beta \cdot \mathrm{cs} \text {. }
$$

The overall social welfare is determined by

$$
\mathrm{zs}^{c}=z^{c}+\mathrm{cs} \text {. }
$$

Proposition 1. In the centralized decision model, the optimal online selling price $\left(p d^{C *}\right)$, optimal offline selling price $\left(p r^{C *}\right)$, product green level $\left(e^{C *}\right)$, the profit of the DCGSC $\left(z^{C *}\right)$, and overall social welfare $\left(z s^{C *}\right)$ are calculated as follows:

$$
\begin{aligned}
\operatorname{pr}^{C *}=\operatorname{pd}^{C *} & =\frac{\left[\mathrm{cmk}(1-\alpha)+\mathrm{ku}(1-\beta+\alpha \beta)-2 \mathrm{~cm} \lambda^{2}\right]}{\delta_{1}}, \\
e^{C *} & =2 \lambda \frac{(u-\mathrm{cm}+\alpha \mathrm{cm})}{\delta_{1}}, \\
z^{C *} & =2 k[u-\mathrm{cm}(1-\alpha)]^{2} \frac{\left[k(1-\alpha)-\lambda^{2}-\beta k(\alpha-1)^{2}\right]}{\delta_{1}^{2}}, \\
\mathrm{zs}^{C *} & =k[u-\mathrm{cm}(1-\alpha)]^{2} \frac{\left[\left(3-4 a+a^{2}\right) k-2 \lambda^{2}-2 \beta k(\alpha-1)^{2}\right]}{\delta_{1}^{2}},
\end{aligned}
$$

where $\delta_{1}=2 k(1-\alpha)-2 \lambda^{2}-\beta k(\alpha-1)^{2}$.

The optimal demand function of the online direct channel and the offline channel is given by

$$
\mathrm{qr}^{C *}=\mathrm{qd}^{C *}=\frac{k(1-\alpha)(u-\mathrm{cm}+\alpha \mathrm{cm})}{\delta_{1}} .
$$

Now, taking the first-order derivative of equation (7) with respect to $e, \mathrm{pr}$, and $\mathrm{pd}$, we can obtain the Hessian matrix, $H\left(\mathrm{St}^{\mathrm{C}}\right)$, as follows:

$$
H\left(\mathrm{St}^{C}\right)=\left[\begin{array}{ccc}
2 \beta \lambda^{2}-k & \lambda-\beta \lambda(1-\alpha) & \lambda-\beta \lambda(1-\alpha) \\
\lambda-\beta \lambda(1-\alpha) & \beta\left(\alpha^{2}+1\right)-2 & 2 \alpha(1-\beta) \\
\lambda-\beta \lambda(1-\alpha) & 2 \alpha(1-\beta) & \beta\left(\alpha^{2}+1\right)-2
\end{array}\right] .
$$

Obviously, $H\left(\mathrm{St}^{C}\right)_{11}=2 \beta \lambda^{2}-k, H\left(\mathrm{St}^{C}\right)_{22}=\left[2-\beta\left(\alpha^{2}+\right.\right.$ 1)] $\left(k-2 \beta \lambda^{2}\right)-[\lambda-\beta \lambda(1-\alpha)]^{2}$, and $H\left(\mathrm{St}^{\mathrm{C}}\right)_{33}=(\alpha+1)(2$ $-\beta-\alpha \beta)\left[2 \lambda^{2}+(\alpha-1)^{2} \beta k-2 k(1-\alpha)\right]$. The Hessian matrix of $H\left(\mathrm{St}^{\mathrm{C}}, e, \mathrm{pr}, \mathrm{pd}\right)$ must be negative definite; to achieve $H\left(\mathrm{St}^{C}\right)_{11}<0, H\left(\mathrm{St}^{C}\right)_{22}>0$, and $H\left(\mathrm{St}^{C}\right)_{33}<0$, the following conditions must be satisfied: $k>2 \beta \lambda^{2}$ and $k>2 \lambda^{2} /[2(1-\alpha)$ $-(1-\alpha)^{2} \beta$ ]. Combining $\partial \mathrm{St}^{c} / \partial e=0, \partial \mathrm{St}^{c} / \partial \mathrm{pr}=0$, and $\partial \mathrm{St}^{c} / \partial \mathrm{pd}=0$, we can obtain $e^{C *}, \mathrm{pr}^{C *}$, and $\mathrm{pd}^{C *}$; then, substituting $e^{C *}, \mathrm{pr}^{C *}$, and $\mathrm{pd}^{C *}$ into equation (7), we can obtain the optimal profit of the DCGSC $\left(z^{C *}\right)$ and the overall social welfare $\left(z s^{C *}\right)$, as shown in Proposition 1. This completes the proof.

2.3. The Manufacturer Independently Undertakes the CSR Model (M). In the M model, since the manufacturer is a Stackelberg leader in the DCGSC, the game order of the 
TABLE 1: List of superscripts and decision variables.

\section{Superscripts}

C

$M$

MR

MRD

Decision variables

$\mathrm{cs}^{j}$

$e^{j}$

$w^{j}$

$\operatorname{pr}^{j}$

$\mathrm{pd}^{j}$

$\mathrm{zm}^{j}$

$\mathrm{zr}^{j}$

$z^{j}$

$\mathrm{zs}^{j}$

$X^{j *}$

manufacturer and the retailer is as follows: the manufacturer decides the online selling price $\left(\mathrm{pd}^{M}\right)$, the product green level $\left(e^{M}\right)$, and the wholesale price $\left(w^{M}\right)$. The retailer decides the offline selling price $\left(\mathrm{pr}^{M}\right)$.

The utility functions of the manufacturer in the DCGSC can be obtained as

$$
\mathrm{Sm}^{M}=(\mathrm{pd}-\mathrm{cm}) \mathrm{qd}+(w-\mathrm{cm}) \mathrm{qr}-\mathrm{ce}+\beta \cdot \mathrm{cs} .
$$

The profit of retailer in the DCGSC can be obtained as

$$
\mathrm{zr}^{M}=(\mathrm{pr}-w) \mathrm{qr} .
$$

The profit of the manufacturer in the DCGSC can be obtained as
Centralized model

Decentralized model (manufacturer independently undertakes CSR model)

Decentralized model (manufacturer and retailer cooperatively undertake CSR model) Collaboration contract model

$$
j \in\{C, M, \mathrm{MR}, \mathrm{MRD}\}
$$

Consumer surplus of the DCGSC

The green manufacturing level

The wholesale price

The online selling price

The offline selling price

Results from manufacturer

Results from retailer

Results from the DCGSC

Results from social welfare Optimal results
Proposition 2. In the $M$ model, the optimal online selling price $\left(p d^{M *}\right)$, optimal offline selling price $\left(p r^{M *}\right)$, product green level $\left(e^{M *}\right)$, the profit of the manufacturer $\left(\mathrm{zm}^{M *}\right)$, the profit of retailer $\left(z r^{M *}\right)$, the DCGSC $\left(z^{M *}\right)$, and the overall social welfare e $\left(z s^{M *}\right)$ are as follows:

$$
\begin{aligned}
\operatorname{pr}^{M *} & =\frac{\left[\operatorname{cmk}\left(2-\beta-2 \alpha^{2}+\alpha^{2} \beta\right)+\mathrm{ku}\left(6+\beta^{2}-2 \alpha-5 \beta+\alpha \beta+2 \alpha^{2} \beta-\alpha^{2} \beta^{2}\right)+\varsigma_{3}\right]}{\varsigma_{1}}, \\
\operatorname{pd}^{M *} & =\frac{\left[\operatorname{cmk}\left(4-4 \alpha-\beta+\alpha^{2} \beta\right)+\mathrm{ku}\left(\beta^{2}+4-5 \beta+\alpha \beta+2 \alpha^{2} \beta-\alpha^{2} \beta^{2}\right)+\varsigma_{3}\right]}{\varsigma_{1}}, \\
w^{M *} & =\frac{\left[\operatorname{cmk}\left(4-4 \alpha-2 \beta+\alpha \beta+2 \alpha \beta^{2}-\alpha^{3} \beta\right)+\mathrm{ku}\left(\beta^{2}+4-4 \beta+\alpha \beta+\alpha^{2} \beta-\alpha^{2} \beta^{2}\right)+\varsigma_{3}\right]}{\varsigma_{1}} .
\end{aligned}
$$

The optimal product green level is

$$
e^{M *}=\frac{\left[2 \operatorname{cm} \lambda\left(2 \alpha-3+\beta+\alpha^{2}-\alpha^{2} \beta\right)+2 \lambda u(3+\alpha-\beta-\alpha \beta)\right]}{\varsigma_{1}} .
$$


We then obtain the maximum profits for the manufacturer and retailer:

$$
\begin{aligned}
& \left\{-k(u-\mathrm{cm}+\alpha \mathrm{cm})^{2}\left[2 \beta^{2}(\alpha+1)^{2}-4 \beta\left(\alpha^{2}+4 \alpha+3\right)+2(\alpha+3)^{2}\right] \lambda^{2}+\left[\left(2 \beta^{3}\left(\alpha^{2}-1\right)^{2}\right.\right.\right. \\
\mathrm{zm}^{M *}= & \frac{\left.\left.-\left(5 \alpha^{4}+6 \alpha^{3}-20 \alpha^{2}-6 \alpha+15\right) \beta^{2}+4\left(\alpha^{4}+2 \alpha^{3}-3 \alpha^{2}-3 \alpha+4\right) \beta+8 \alpha^{2}+16 \alpha-24\right] k\right\}}{\varsigma_{1}^{2}} \\
\mathrm{zr}^{M *} & =\frac{k^{2}(1-\alpha)^{2}(u-\mathrm{cm}+\alpha \mathrm{cm})^{2}(\alpha \beta-2+\beta)^{2}}{\varsigma_{1}^{2}} .
\end{aligned}
$$

Finally, we obtain the maximum profits of the supply chain and social welfare:

$$
\begin{aligned}
& z^{M *}=\frac{\left\{-2 k(u-\mathrm{cm}+\alpha \mathrm{cm})^{2} \varsigma_{2} \lambda^{2}+\left[\left(\beta^{3}\left(\alpha^{2}-1\right)^{2}-\left(3 \alpha^{4}+3 \alpha^{3}-11 \alpha^{2}-3 \alpha+8\right) \beta^{2}+2 \beta\left(\alpha^{4}+3 \alpha^{3}-7 \alpha^{2}-7 \alpha+10\right)+2\left(\alpha^{2}+6 \alpha-7\right)\right] k\right\}\right.}{\varsigma_{1}^{2}}, \\
& \mathrm{zs}^{M *}=\frac{\left\{-k(u-\mathrm{cm}+\alpha \mathrm{cm})^{2} \varsigma_{2} \lambda^{2}+\left[\left(2 \beta^{3}\left(\alpha^{2}-1\right)^{2}-\left(7 \alpha^{4}+6 \alpha^{3}-24 \alpha^{2}-6 \alpha+17\right) \beta^{2}+2 \beta\left(3 \alpha^{4}+8 \alpha^{3}-18 \alpha^{2}-16 \alpha+23\right)-2 \alpha^{4}-4 \alpha^{3}+8 \alpha^{2}+36 \alpha-38\right] k\right\}\right.}{\varsigma_{1}^{2}} .
\end{aligned}
$$

The optimal demand functions of the online direct channel and the offline channel are given by

$$
\begin{aligned}
\operatorname{qr}^{M *} & =\frac{k(1-\alpha)(2-\beta-\alpha \beta)(u-\mathrm{cm}+\alpha \mathrm{cm})}{\varsigma_{1}}, \\
\mathrm{qd}^{M *} & =\frac{k(1-\alpha)(2 \alpha-\beta-\alpha \beta+4)(u-\mathrm{cm}+\alpha \mathrm{cm})}{\varsigma_{1}},
\end{aligned}
$$

where

$$
\begin{aligned}
\varsigma_{1}= & 2 \lambda^{2}(\alpha \beta-\alpha+\beta-3) \\
& +\left[\left(\alpha^{3}-\alpha^{2}-\alpha+1\right) \beta^{2}-2 \beta\left(\alpha^{3}-\alpha^{2}-3 \alpha+3\right)+8-8 \alpha\right] k, \\
\varsigma_{2}= & 2 \beta^{2}(\alpha+1)^{2}-4 \beta\left(\alpha^{2}+4 \alpha+3\right)+2(\alpha+3)^{2}, \\
\varsigma_{3}= & 2 \mathrm{~cm} \lambda^{2}(\beta-3-\alpha+\alpha \beta) .
\end{aligned}
$$

Proof. Since the second-order derivatives of $\mathrm{zr}^{M}$ and $\partial^{2} \mathrm{zr}^{M} / \partial^{2} \mathrm{pr}=-2$ are negative, we have $\partial \mathrm{zr}^{M} / \partial \mathrm{pr}=u-2 \mathrm{pr}+w+\lambda e+\alpha \mathrm{pd}=0 ;$

thenpr $=(u+w+\lambda e+\alpha \mathrm{pd}) / 2$. Substituting pr into equation (13) and then taking the first-order derivative of equation (14) with respect to $e, w$, and $\mathrm{pd}$, we can obtain the Hessian matrix $H\left(\mathrm{sm}^{M}\right)$ as follows:

$$
H\left(\mathrm{Sm}^{M}\right)=\left[\begin{array}{ccc}
h_{1} & h_{2} & h_{3} \\
h_{2} & h_{4} & \alpha h_{4} \\
h_{5} & \alpha h_{4} & h_{6}
\end{array}\right],
$$

where $h_{1}=\left[\left(\alpha^{2}+4 \alpha+5\right) \beta \lambda^{2}-4 k\right] / 4, h_{2}=\lambda\left[\left(\alpha^{2}+2 \alpha-1\right)^{2}\right.$ $\beta+2] / 4, \quad h_{3}=\lambda\left[2 \alpha-\left(4+\alpha-2 \alpha^{2}-\alpha^{3}\right) \beta+4\right] / 4$, $h_{4}=\left(\beta \alpha^{2}+\beta-4\right) / 4, h_{5}=\lambda\left[2 \alpha+4+\left(2 \alpha^{2}+\alpha^{3}-4-\alpha\right) \beta\right] / 4$, and $h_{6}=\left[\left(4-3 \alpha^{2}+\alpha^{4}\right) \beta+4\left(\alpha^{2}-2\right)\right] / 4$.

Then $\pi\left(\mathrm{Sm}^{M}\right)_{11}=\left[\left(\alpha^{2}+4 \alpha+5\right) \beta \lambda^{2}-4 k\right] / 4$.

$$
\pi\left(\mathrm{Sm}^{M}\right)_{22}=\frac{\left\{\left[(\alpha+1)^{2} \beta^{2}-2\left(\alpha^{2}+3 \alpha+2\right) \beta-1\right] \lambda^{2}+k\left(4-\beta-\alpha^{2} \beta\right)\right\}}{4}
$$

$\pi\left(\mathrm{Sm}^{M}\right)_{33}=-(\alpha+1)\left[k \beta^{2}\left(\alpha^{3}-\alpha^{2}-\alpha+1\right)-2 k \alpha \beta\right.$ $\left.\left(\alpha^{2}-\alpha-3\right)-2 k(4 \alpha+3 \beta-4 k)+2 \lambda^{2}(\alpha \beta-\alpha+\beta-3)\right] / 4$. The Hessian matrix of $H\left(\mathrm{Sm}^{M}\right)$ is negative definite for $e, w$, and pd if $k>\left(\alpha^{2}+4 \alpha+5\right) \beta \lambda^{2} / 4, \quad \pi\left(\mathrm{Sm}^{M}\right)_{11}<0$, $\pi\left(\mathrm{Sm}^{M}\right)_{22}>0$, and $\pi\left(\mathrm{Sm}^{M}\right)_{33}<0$. Thus, $\mathrm{Sm}^{M}$ is strictly jointly concave in $e, w$, and pd; combining $\partial \mathrm{Sm}^{M} / \partial e=0$, $\partial \mathrm{Sm}^{M} / \partial w=0$, and $\partial \mathrm{Sm}^{M} / \partial \mathrm{pd}=0$, we can derive Proposition 2 , so the results are straightforward to derive.

2.4. The Manufacturer and Retailer Cooperatively Undertake the CSR Model (MR). In the MR model, the manufacturer and retailer share the cost of CSR. However, the manufacturer 
is the leader who decides the online selling price $\left(\mathrm{pd}^{\mathrm{MR}}\right)$, product green level of the green product $\left(e^{\mathrm{MR}}\right)$, and wholesale price $\left(w^{\mathrm{MR}}\right)$. The retailer is a follower who decides the offline selling price $\left(\mathrm{pr}^{\mathrm{MR}}\right)$. The utility functions of the manufacturer and the retailer in the DCGSC can, respectively, be given as

$$
\begin{aligned}
\mathrm{Sm}^{\mathrm{MR}} & =(\mathrm{pd}-\mathrm{cm}) \mathrm{qd}+(w-\mathrm{cm}) \mathrm{qr}-\mathrm{ce}+\beta \cdot \mathrm{csd}, \\
\mathrm{Sr}^{\mathrm{MR}} & =(\mathrm{pr}-w) \mathrm{qr}+\beta \cdot \mathrm{csr} .
\end{aligned}
$$

The manufacturer's profit is given by

$$
\mathrm{zm}^{\mathrm{MR}}=\mathrm{Sm}^{\mathrm{MR}}-\beta \cdot \mathrm{csd} .
$$

The retailer's profit is given by

$$
\mathrm{zr}^{\mathrm{MR}}=\mathrm{Sr}^{\mathrm{MR}}-\beta \cdot \operatorname{csr} .
$$

The overall social welfare is given by

$$
\mathrm{zs}^{\mathrm{MR}}=\mathrm{zm}^{\mathrm{MR}}+\mathrm{zr}^{\mathrm{MR}}+\mathrm{cs} \text {. }
$$

Proposition 3. In the MR model, the optimal online selling price $\left(p r^{M R *}\right)$, optimal offline selling price $\left(p d^{M R *}\right)$, product green level $\left(e^{M R *}\right)$, the profit of the manufacturer $\left(z m^{M R *}\right)$, the profit of the retailer $\left(z r^{M R *}\right)$, the profit of the DCGSC $\left(z^{M R *}\right)$, and the overall social welfare $\left(z s^{M R *}\right)$ are as follows:

$$
\begin{aligned}
\operatorname{pr}^{\mathrm{MR} *}= & \frac{\left\{\operatorname{cmk}\left[\left(2 \alpha^{2}-\alpha-1\right) \beta-2 \alpha^{2}+2\right]+k u\left[\left(2-2 \alpha^{2}\right) \beta^{2}+\left(2 \alpha^{2}+2 \alpha-7\right) \beta-2 \alpha+6\right]+\theta_{3}\right\}}{\theta_{1}}, \\
\operatorname{pd}^{\mathrm{MR} *} & =\frac{\left\{\operatorname{cmk}\left[\left(\alpha^{2}+\alpha-2\right) \beta+4-4 \alpha\right]+k u\left[\left(2-2 \alpha^{2}\right) \beta^{2}+\left(2 \alpha^{2}+\alpha-6\right) \beta+4\right]+\theta_{3}\right\}}{\theta_{1}}, \\
w^{\mathrm{MR} *} & =\frac{\left\{\operatorname{cmk}\left[\left(\alpha^{3}-\alpha^{2}-\alpha+1\right) \beta^{2}-\beta\left(\alpha^{3}-\alpha^{2}-4 \alpha+4\right)+4-4 \alpha\right]+\mathrm{ku}\left[\left(1-\alpha^{2}\right) \beta^{2}+\left(\alpha^{2}-4\right) \beta+4\right]+\theta_{3}\right\}}{\theta_{1}} .
\end{aligned}
$$

The optimal product green level is

$$
e^{\mathrm{MR} *}=\frac{\lambda(2 \alpha-3 \beta+6-3 \alpha \beta)(u-\mathrm{cm}+\alpha \mathrm{cm})}{\theta_{1}} .
$$

We then obtain the maximum profits for the manufacturer and retailer:

$\mathrm{zm}^{\mathrm{MR} *}=\frac{\left\{-k^{2}(u-\mathrm{cm}+\alpha \mathrm{cm})^{2}\left\{\theta_{2} \lambda^{2}+\left[10 \beta^{3}\left(\alpha^{2}-1\right)^{2}-2 \beta^{2}\left(9 \alpha^{4}+8 \alpha^{3}-35 \alpha^{2}-8 \alpha+26\right)+8 \beta\left(\alpha^{4}+2 \alpha^{3}-8 \alpha^{2}-6 \alpha+11\right)+16(\alpha-1)(\alpha+3)\right] k\right\}\right\}}{\left(2 \theta_{1}^{2}\right)}$,

$\mathrm{zr}^{\mathrm{MR} *}=\frac{[k(\alpha-1)(u-\mathrm{cm}+\alpha \mathrm{cm})(\beta+\alpha \beta-2)]^{2}(1-\beta)}{\left(2 \theta_{1}^{2}\right)}$.

Finally, we obtain the maximum profits of the supply chain and social welfare:

$$
\begin{aligned}
\mathrm{z}^{\mathrm{MR} *}= & \frac{-k(u-\mathrm{cm}+\alpha \mathrm{cm})^{2}\left\{\theta_{2} \lambda^{2}+\left[12 \beta^{3}\left(\alpha^{2}-1\right)^{2}-2 \beta^{2}\left(10 \alpha^{4}+12 \alpha^{3}-41 \alpha^{2}-12 \alpha+31\right)+8 \beta\left(\alpha^{4}+3 \alpha^{3}-8 \alpha^{2}-9 \alpha+13\right)+8(\alpha-1)(\alpha+7)\right] k\right\}}{\left(2 \theta_{1}^{2}\right)}, \\
\mathrm{zs}^{\mathrm{MR} *}= & \frac{-k(u-\mathrm{cm}+\alpha \mathrm{cm})^{2}\left\{\theta_{2} \lambda^{2}+\left[12 \beta^{3}\left(\alpha^{2}-1\right)^{2}-\beta^{2}\left(25 \alpha^{4}+24 \alpha^{3}-92 \alpha^{2}-24 \alpha+67\right)+4 \beta\left(4 \alpha^{4}+9 \alpha^{3}-23 \alpha^{2}-21 \alpha+31\right)-4\left(\alpha^{4}+2 \alpha^{3}-4 \alpha^{2}-18 \alpha+19\right)\right] k\right\}}{\left(2 \theta_{1}^{2}\right)} .
\end{aligned}
$$


The optimal demand functions of the online direct channel and the offline channel are given by

$$
\begin{aligned}
\mathrm{qr}^{\mathrm{MR} *} & =\frac{k(1-\alpha)(2-\beta-\alpha \beta)(u-\mathrm{cm}+\alpha \mathrm{cm})}{\theta_{1}}, \\
\mathrm{qd}^{\mathrm{MR} *} & =\frac{2 k(1-\alpha)(2-\alpha+\beta+\alpha \beta)(u-\mathrm{cm}+\alpha \mathrm{cm})}{\theta_{1}},
\end{aligned}
$$

where

$$
\begin{aligned}
\theta_{1}= & \lambda^{2}(3 \beta-2 \alpha+3 \alpha \beta-6) \\
& +\left[2 \beta^{2}\left(\alpha^{3}-\alpha^{2}-\alpha+1\right)-2 \beta\left(\alpha^{3}-\alpha^{2}-4 \alpha+4\right)+8-8 \alpha\right] k, \\
\theta_{2}= & 9 \beta^{2}(a+1)^{2}-12 \beta(\alpha+1)(\alpha+3)+4(a+3)^{2}, \\
\theta_{3}= & \operatorname{cm} \lambda^{2}(3 \beta-2 \alpha+3 \alpha \beta-6) .
\end{aligned}
$$

Proof. Taking the second-order partial derivatives of $\mathrm{Sr}^{\mathrm{MR}}$ with respect to $\mathrm{pr}$, we have $\partial^{2} \mathrm{Sr}^{\mathrm{MR}} / \partial^{2} \mathrm{pr}=\beta-2<0$, when $\partial \mathrm{Sr}^{\mathrm{MR}} / \partial \mathrm{pr}=0 . \quad \mathrm{We}$ get $\mathrm{pr}=[u+w+\lambda e+\alpha \mathrm{pd}-\beta(u+\lambda e+\alpha \mathrm{pd})] /(2-\beta)$.

Substituting pr into equation (25), taking the second-order partial derivatives of $\mathrm{Sm}^{\mathrm{MR}}$ with respect to $e, w$, and $\mathrm{pd}$, respectively, we have the Hessian matrix $H\left(\mathrm{Sm}^{\mathrm{MR}}\right)$ :

$$
H\left(\mathrm{Sm}^{\mathrm{MR}}\right)=\left[\begin{array}{lll}
h_{11} & h_{12} & h_{13} \\
h_{2} & h_{22} & h_{23} \\
h_{2} & h_{3} & h_{33}
\end{array}\right],
$$

where $\quad h_{11}=\beta\{\lambda-[\alpha \lambda(1-\beta)] /(\beta-2)\}^{2}-k, \quad h_{12}=\lambda[2-$ $\left.\left(a^{2}+a\right) \beta^{2}+\left(a^{2}+2 a-1\right) \beta\right] /(\beta-2)^{2}, h_{13}=\lambda[2 \alpha-(4+\alpha$ $\left.\left.-2 \alpha^{2}-\alpha^{3}\right) \beta+4\right] / 4, h_{21}=h_{31}=\left\{2-\lambda\left[\left(\alpha^{2}+\alpha\right) \beta^{2}+\left(\alpha^{2}+\right.\right.\right.$ $2 \alpha-1) \beta]\} /(\beta-2)^{2}, h_{23}=\left\{\alpha\left[\left(1-\alpha^{2}\right) \beta^{2}+\left(\alpha^{2}-4\right) \beta+4\right]\right\} /$ $(\beta-2)^{2}, h_{22}=h_{32}=\left(\beta \alpha^{2}+2 \beta-4\right) /(\beta-2)^{2}$, and $h_{33}=$ $\left[2 \alpha^{2}(\beta-1)\right] /(\beta-2)+\left[\beta\left(\beta-\alpha^{2} \beta+\alpha^{2}-2\right)^{2}\right] /(\beta-2)^{2}-2$. We have

$$
\begin{aligned}
& \pi\left(\mathrm{Sm}^{\mathrm{MR}}\right)_{11}=\beta\left[\frac{\alpha(\beta-1)}{(\beta-2)}+1\right]^{2} \lambda^{2}-k \\
& \pi\left(\mathrm{Sm}^{\mathrm{MR}}\right)_{22}=\frac{\left\{\left[2 \beta^{2}(\alpha+1)^{2}-2 \beta\left(\alpha^{2}+3 \alpha+1\right)-1\right] \lambda^{2}+\left(4-\beta \alpha^{2}-2 \beta\right) k\right\}}{(\beta-2)^{2}}, \\
& \pi\left(\mathrm{Sm}^{\mathrm{MR}}\right)_{33}=\frac{(\alpha+1)\left\{\left[2 \beta^{2}(\alpha+1)^{2}+2 \beta(\alpha+1)(\alpha+2)-1\right] \lambda^{2}+k\left(\beta \alpha^{2}-4+2 \beta\right)\right\}(\alpha b-\beta-\alpha+2)\left[\left(\alpha^{2}-1\right) \beta^{2}+\left(4-\alpha^{2}\right) \beta-4\right]}{(\beta-2)^{4}} .
\end{aligned}
$$

The Hessian matrix of $H\left(\mathrm{Sm}^{\mathrm{MR}}\right)$ is negative definite fore, $w$, and pd. If $k>\beta[\alpha(\beta-1) /(\beta-2)+1]^{2} \lambda^{2}, \pi\left(\mathrm{Sm}^{\mathrm{MR}}\right)_{11}<0$, $\pi\left(\mathrm{Sm}^{\mathrm{MR}}\right)_{22}>0$, and $\pi\left(\mathrm{Sm}^{\mathrm{MR}}\right)_{33}<0, \mathrm{Sm}^{\mathrm{MR}}$ is strictly jointly concave in $e, w$, and pd, solving $\partial \mathrm{Sm}^{\mathrm{MR}} / \partial e=0$, $\partial \mathrm{Sm}^{\mathrm{MR}} / \partial w=0$, and $\partial \mathrm{Sm}^{\mathrm{MR}} / \partial \mathrm{pd}=0$; we can derive Proposition 3; therefore, the results are straightforward to derive.

2.5. Collaboration Contract Model (MRD). In the MRD model, the manufacturer and retailer work together to optimize the profit of the DCGSC. The retailer actively shares the cost of CSR, the manufacturer shares $g$, which is the proportion of the online profit to the retailer, and the retailer pays a franchise fee $(f)$ to the manufacturer. Similar to the $M$ and MR models, the manufacturer is a leader in prioritizing and deciding the online selling price $\left(\mathrm{pd}^{\mathrm{MRD}}\right)$, product green level $\left(e^{\mathrm{MRD}}\right)$, and wholesale price $\left(w^{\mathrm{MRD}}\right)$, and then the retailer is a follower to decide the offline selling price ( $\mathrm{pr}^{\mathrm{MRD}}$ ) to maximize the profit. The utility functions of the manufacturer and the retailer in the DCGSC are, respectively,

$$
\begin{aligned}
\mathrm{Sm}^{\mathrm{MRD}} & =(1-g)(\mathrm{pd}-\mathrm{cm}) \mathrm{qd}+(w-\mathrm{cm}) \mathrm{qr}-\mathrm{ce}+\beta \cdot \mathrm{csd}+f, \\
\mathrm{Sr}^{\mathrm{MRD}} & =(\mathrm{pr}-w) \mathrm{qr}+\beta \cdot \mathrm{csr}+g(\mathrm{pd}-\mathrm{cm}) \mathrm{qd}-f .
\end{aligned}
$$

The retailer's profit is given by

$$
\mathrm{zm}^{\mathrm{MRD}}=\mathrm{Sm}^{\mathrm{MRD}}-\beta \cdot \mathrm{csd} .
$$

The manufacturer's profit is given by

$$
\mathrm{zr}^{\mathrm{MRD}}=\mathrm{Sr}^{\mathrm{MRD}}-\beta \cdot \mathrm{csr} \text {. }
$$

The overall social welfare is given by

$$
\mathrm{zs}^{\mathrm{MRD}}=\mathrm{zm}^{\mathrm{MRD}}+\mathrm{zr}^{\mathrm{MRD}}+\mathrm{cs} \text {. }
$$

Taking the second-order partial derivatives of $\mathrm{Sr}^{\mathrm{MRD}}$ with respect to $\mathrm{pr}$, we have $\partial^{2} \mathrm{Sr}^{\mathrm{MRD}} / \partial^{2} \mathrm{pr}=\beta-2<0$; that is, the retailer's profit $\left(\mathrm{Sr}^{\mathrm{MRD}}\right)$ will be concave; when $\partial \mathrm{Sr}^{\mathrm{MRD}}$ / $\partial \mathrm{pr}=u-2 \mathrm{pr}+w+\lambda e+\alpha \mathrm{pd}-\beta(u-\mathrm{pr}+\lambda e+\alpha \mathrm{pd})$ is zero, we get $\mathrm{pr}=[u+w+\lambda e+\alpha \mathrm{pd}-\beta(u+\lambda e+\alpha \mathrm{pd})] /(2-\beta)$.

Substituting into equation (15) and taking the secondorder partial derivatives of $\mathrm{Sm}^{\mathrm{MRD}}$ with respect to $\mathrm{pd}$, 
$\partial^{2} \mathrm{Sm}^{\mathrm{MRD}} / \partial^{2} \mathrm{pd}=\beta\left[\alpha^{2} / 4+\left(\alpha^{2} / 2-1\right)^{2}\right]+\alpha^{2}-2<0$; that is, the manufacturer's profit $\left(\mathrm{Sm}^{\mathrm{MRD}}\right)$ will be concave; when $\partial \mathrm{Sm}^{\mathrm{MRD}} / \partial \mathrm{pd}=0$, we obtain that

$$
\begin{aligned}
\mathrm{pd}= & {\left[\left(2 \alpha \beta-4 \alpha+\alpha^{3} \beta\right) g-\left(\alpha^{3}-\alpha\right) \beta^{2}+\left(\alpha^{3}-4 \alpha\right) \beta+4 \alpha\right] w+\left(\eta_{1} g+\eta_{2}\right) u+\eta_{1} e g+\eta_{2} e \lambda } \\
& +\left(4 \alpha^{2}-\alpha^{4} \beta-2 \alpha^{2} \beta\right) \mathrm{cmg}^{2}+\eta_{3} \mathrm{cmg}+\left[\left(1-\alpha^{2}\right) \beta^{2}+\left(3 \alpha^{2}+\alpha-4\right) \beta-2 \alpha^{2}-2 \alpha+4\right] \mathrm{cm},
\end{aligned}
$$

where

$$
\begin{aligned}
& \eta_{1}=\left(-\alpha^{3}-\alpha^{2}-\alpha-1\right) \beta^{2}+\left(\alpha^{3}+2 \alpha^{2}+3 \alpha+4\right) \beta-2 \alpha-4, \\
& \eta_{2}=\left(\alpha^{3}+\alpha^{2}-\alpha-1\right) \quad \beta^{3} \quad+\left(-2 \alpha^{3}-3 \alpha^{2}+4 \alpha+5\right) \beta^{2} \\
& +\left(\alpha^{3}+2 \alpha^{2}-5 \alpha-8\right) \beta+2 \alpha+4, \quad \text { and } \eta_{3}=\left(\alpha^{4}-1\right) \beta^{2}+ \\
& \left(-\alpha^{4}+\alpha^{2}-\alpha+4\right) \beta-2 \alpha^{2}+2 \alpha-4 .
\end{aligned}
$$

To achieve coordination in the supply chain, the optimal decision in the decentralized situation must be consistent with the optimal decision in the centralized situation; that is, the combination contract optimization coordination needs to meet the following conditions:

$$
\left\{\begin{array}{l}
e^{C *}=e^{\mathrm{MRD} *}, \\
\mathrm{pr}^{\mathrm{C} *}=\mathrm{pr}^{\mathrm{MRD} *}, \\
\mathrm{pd}^{\mathrm{C} *}=\mathrm{pd}^{\mathrm{MRD} *} .
\end{array}\right.
$$

Proposition 4. When the combination contract satisfies equation (43), the DCGSC can be coordinated. In the MRD model, the optimal wholesale price and the profits of the manufacturer and the retailer are as follows:

$$
\begin{aligned}
& {\left[\nu_{1}+(1-\alpha) \beta^{2}+\left(-\alpha^{3}+2 \alpha-4\right) \beta+4\right] \mathrm{ku}+\left(2 \beta a^{2}+4 \beta-8\right) \mathrm{cm} \lambda^{2}+\left\{\left[\left(\alpha^{5}-2 \alpha^{4}\right.\right.\right.} \\
& \left.\left.+3 \alpha^{3}-4 \alpha^{2}+2 \alpha\right) \beta^{2}+\left(\alpha^{4}-5 \alpha^{3}+10 \alpha^{2}-6 \alpha\right) \beta-4 \alpha^{2}+4 \alpha\right] \mathrm{cmg}+\left[\left(\alpha^{4}-2 \alpha^{3}+2 \alpha^{2}\right.\right. \\
& w^{\mathrm{MRD} *}=\frac{\left.\left.-2 \alpha+1) \beta^{2}+\left(-\alpha^{4}+3 \alpha^{3}-4 \alpha^{2}+6 \alpha-4\right) \beta+4-4 \alpha\right] \mathrm{cm}\right\} k}{\left[\left(\beta \alpha^{2}+2 \beta-4\right) \tau\right]}, \\
& g^{\mathrm{MRD} *}=\frac{\left\{\chi_{1}+\left[\left(\alpha^{2}-1\right)\left(\beta \alpha^{2}+2 \beta-4\right)\left(\alpha^{6}+\alpha^{4}-2 \alpha^{2}\right) \beta^{5}-\chi_{2}+\chi_{3}+\chi_{4}-16 \alpha^{2}+16\right]^{(1 / 2)}-8\right\}}{\left[\left(\alpha^{5}+\alpha^{3}-2 \alpha\right) 2 \beta^{2}+\left(\alpha^{4}-4 \alpha^{3}+2 \alpha^{2}+4 \alpha\right) 2 \beta-8 \alpha^{2}\right]} .
\end{aligned}
$$

where $\chi_{1}=\left(\alpha^{5}+\alpha^{3}-2 \alpha\right) \beta^{3}-\left(\alpha^{5}-\alpha^{4}+5 \alpha^{3}-\alpha^{2}-6 \alpha+2\right)$ $\beta^{2}+\left(4 \alpha^{3}-2 \alpha^{2}-4 \alpha+8\right) \beta, \quad \chi_{2}=2 \beta^{4}\left(\alpha^{6}-\alpha^{5}+3 \alpha^{4}-3 \alpha^{3}-\right.$ $\left.4 \alpha^{2}+4 \alpha\right), \chi_{3}=\beta^{3}\left(\alpha^{6}-6 \alpha^{5}+10 \alpha^{4}-26 \alpha^{3}-5 \alpha^{2}+44 \alpha-2\right)$, and $\chi_{4}=4 \beta^{2}\left(\alpha^{5}-2 \alpha^{4}+9 \alpha^{3}-5 \alpha^{2} \quad-20 \alpha+3\right)+4 \beta\left(\alpha^{4}-\right.$ $\left.4 \alpha^{3}+9 \alpha^{2}+12 \alpha-6\right)$.
Substituting equation (43) and $w^{M R D}$ into equations (39) and (40), respectively, the profits of the manufacturer and retailer in the DCGSC can be obtained as

$$
\begin{aligned}
\mathrm{zm}^{\mathrm{MRD} *} & =f-\frac{2 k \lambda^{2}(u-\mathrm{cm}+\alpha \mathrm{cm})^{2}}{\tau^{2}}+v_{6}\left[(\alpha-1) \beta^{2}-v_{1}+\left(\alpha^{3}-2 \alpha+4\right) \beta-4\right]+v_{2}(g-1), \\
\mathrm{zr}^{\mathrm{MRD} *} & =-f+\frac{g k^{2}(1-\alpha)(\alpha \beta-\beta+1)(u-\mathrm{cm}+\alpha \mathrm{cm})^{2}}{\tau^{2}}+\left(\nu_{1}+v_{4}\right) v_{6} .
\end{aligned}
$$

where $\quad v_{1}=\left[\left(\alpha^{4}-\alpha^{3}+2 \alpha^{2}-2 \alpha\right) \beta^{2}+\left(\alpha^{3}-4 \alpha^{2}+6 \alpha\right) \beta-\right.$ $4 \alpha] \mathrm{g}, \quad v_{2}=k^{2}(\alpha-1)(\alpha \beta-\beta+1)(u-\mathrm{cm}+\alpha \mathrm{cm})^{2} / \tau^{2}, \quad v_{3}$ $=\left[(3 \beta-2 \alpha+3 \alpha \beta-6) \lambda^{2}+\left[4 \beta^{2}\left(\alpha^{3}-\alpha^{2}-\alpha+1\right)+\left(-2 \alpha^{3}+\right.\right.\right.$ $\left.\left.2 \alpha^{2}+8 \alpha-8\right) \beta-8 \alpha+8\right] k$, and $v_{4}=\left(\alpha^{3}-\alpha^{2}+\alpha-1\right) \beta^{2}+(-$ $\left.\alpha^{3}+\alpha^{2}-2 \alpha+2\right) \beta v_{5}=(\alpha-1) \beta^{2}+\left(\alpha^{3}-2 \alpha+4\right) \beta-4$.

$$
\begin{array}{r}
v_{6}=\frac{k^{2}(1-\alpha)(u-\mathrm{cm}+\alpha \mathrm{cm})^{2}}{\left[\left(\beta \alpha^{2}+2 \beta-4\right) \tau^{2}\right]}, \\
\tau=2 \alpha k-2 k+\beta k+2 \lambda^{2}-2 \alpha \beta k+a^{2} \beta k .
\end{array}
$$

The franchise fee satisfies the condition that $f_{1} \leq f \leq f_{2}$. 


$$
\begin{aligned}
& f_{1}=\frac{\left(2 k \lambda^{2}(u-\mathrm{cm}+\alpha \mathrm{cm})^{2}\right)}{\tau^{2}}-\frac{k(u-\mathrm{cm}+\alpha \mathrm{cm})^{2}\left(\rho_{1} \lambda^{2}+\rho_{2} k\right)}{\left(2 v_{3}^{2}\right)}+\left(v_{5}-v_{1}\right) v_{6}-(g-1) v_{2}, \\
& f_{2}=\frac{k^{2}(a-1)^{2}(\beta-1)(u-\mathrm{cm}+\alpha \mathrm{cm})^{2}(\beta+\alpha \beta-2)^{2}}{v_{3}^{2}}+\left(\nu_{1}+v_{4}\right) v_{6}-g v_{2} .
\end{aligned}
$$

where $\rho_{1}=\left(9 \alpha^{2}+18 \alpha+9\right) \beta^{2}+\left(-12 \alpha^{2}-48 \alpha-36\right) \beta+4 \alpha^{2}+$ $24 \alpha+36$ and $\rho_{2}=\left(10 \alpha^{4}-20 \alpha^{2}+10\right) \beta^{3}+\left(70 \alpha^{2}-18 \alpha^{4}-\right.$ $\left.16 \alpha^{3}+16 \alpha-52\right) \quad \beta^{2}+\left(8 \alpha^{4}+16 \alpha^{3}-64 \alpha^{2}-48 \alpha+88\right) \beta+$ $16 \alpha^{2}+32 \alpha-48$.

Proposition 4 shows that the manufacturer charges a certain franchise fee to compensate for the loss of profits caused by the investment in CSR. At this time, the manufacturer and the retailer reach a combination contract with franchise costs. We assume that the franchise fee is $f$, and the conditions that must be met are $f_{1} \leq f \leq f_{2}$. If the franchise costs exceed the retailer's profit increment $f_{2}$, the retailer's profit in the portfolio contract does not increase, thus rejecting the franchise fee combination contract. However, if the franchise costs are not sufficient to compensate for the manufacturer's loss of profit $f_{1}$, the manufacturer is still in a state of loss of profit, and the manufacturer will also refuse to accept the combination contract with franchise costs. Therefore, only when the franchise costs are between the manufacturer's loss of profit and the retailer's profit increase can they accept the franchise cost combination contract. At this time, both parties' profit diversification decisions will increase their profits; that is, $\mathrm{zm}^{\mathrm{MRD}}>\mathrm{zm}^{\mathrm{MR}}$ and $\mathrm{zr}^{\mathrm{MRD}}>\mathrm{zr}^{\mathrm{MR}}$. In addition, the specific franchise fees depend on the bargaining power of the manufacturer and retailer.

\section{Analytical Results}

By comparing and analyzing the equilibrium results under different strategies, we obtain Proposition 5-9. We then analyze the impact of the CSR coefficient $(\beta)$ on the product green level and obtain the following.

\section{Proposition 5}

(i) The product green level e increases with $\beta$; that is, $\partial e^{j *} / \partial \beta>0, j \in\{C, M, M R, M R D\}$

(ii) Online selling price $p d$ and offline selling price pr decrease with decreasing $\beta$, respectively; that is, $\partial e^{j *} / \partial \beta>0$ and $\partial p d^{j *} / \partial \beta>0, j \in\{C, M, M R, M R D\}$

(iii) All decision variables increase with $\lambda$

Proof. See the Appendix.

Proposition 5 shows that the product green level increases with an increase in the CSR coefficient, $\beta$. Both the online and offline selling prices decrease with an increase in the CSR coefficient, $\beta$. This is because when the green level of products and market demand increase, the manufacturer is more likely to invest in more green products. It shows that increasing CSR not only increases the product green level but also helps in controlling the selling price of green products. Also, when the manufacturer increases attention to consumer surplus, there is increased investment in green products.

The product green level increases with an increase in CGP. Also, online and offline selling prices and market demand increase with an increase in CGP. This means that increasing CGP will motivate companies to invest more in technologies that will improve the product green level. As green investments increase, online and offline selling prices will also increase, and the positive effect of product green level on sales will be higher than the negative effect of price on sales. Thus, CGP will increase product green level, the selling price of the product, and the demand for it, thereby increasing the overall profitability and social welfare of the supply chain.

We now compare the equilibrium results under different decisions and obtain Propositions 6-9.

Proposition 6. $e^{C *}=e^{M R D *}>e^{M R *}>e^{M *}$.

Proof. See the Appendix.

We compare the equilibrium results of the centralized decision-making model, showing the product green level being the highest under centralized decision-making, which provides a benchmark for combination contract coordination. The product green level under the MR model is higher than that in the M model. This is because the retailer shares part of the CSR costs, and the manufacturer is more likely to invest in green technology to improve product green level.

\section{Proposition 7}

(i) $p r^{M *}>p r^{M R *}>p r^{C *}=p r^{M R D *}$; $p d^{C *}=p d^{M R D *}>p d^{M R *}>p d^{M *}$

(ii) $q r^{C *}=q r^{M R D *}>q r^{M R *}>q r^{M *}$; $q d^{M *}>q d^{M R *}>q d^{C *}=q d^{M R D *}$

For proof, see the Appendix.

Proposition 7 shows that the manufacturer and retailer have forged a close relationship under the centralized decision, and the price and market sales under the centralized decision are equal to the combined contract decision. Among them, in the M model, the offline selling price is the highest, and the online selling price is the lowest. Under the coordination of the combination contract, the offline selling price is the lowest, online market sales are the highest, the online selling price is the highest, and offline market sales are the lowest. This is because, in the M model, the manufacturer has obvious advantages to control channels and obtain channel competition advantages at the lower offline selling price. 
However, when the manufacturer bears the cost of CSR independently, there is cost pressure to pay the higher wholesale price offline to the retailer, resulting in the highest offline selling price and a significant online selling price advantage and in the highest online market demand and the lowest offline market demand.

\section{Proposition 8}

$$
\begin{gathered}
\mathrm{zm}^{\mathrm{MRD} *}>\mathrm{zm}^{\mathrm{MR} *}>\mathrm{zm}^{M *}, \\
\mathrm{zr}^{\mathrm{MRD} *}>\mathrm{zr}^{M *}>\mathrm{zr}^{\mathrm{MR} *}
\end{gathered}
$$

For proof, see the Appendix.

Proposition 8 shows that the manufacturers' profit is higher in the MR model than in the M model, and the retailers' profit is higher in the $\mathrm{M}$ model than in the MR model, which indicates that CSR affects the profitability of the DCGSC members. However, under the MRD model, manufacturers' and retailers' profits are higher than those under the MR and M models. This also indicates that the combined coordination mechanism helps the DCGSC achieve Pareto optimality and enhance the profitability of the supply chain enterprises.

\section{Proposition 9}

$$
\begin{gathered}
z^{\mathrm{MRD} *}>z^{\mathrm{MR} *}>z^{M *}, \\
\mathrm{zs}^{\mathrm{MRD} *}>\mathrm{zs}^{\mathrm{MR} *}>\mathrm{zs}^{M *}
\end{gathered}
$$

For the proof, see the Appendix.

Proposition 9 shows that the profits of the DCGSC and social welfare are higher in the MR model than in the M model, which shows that the retailer shares part of the CSR costs, causing the manufacturer's increased marginal revenue to be higher than the retailer's reduced marginal revenue. The profits of the DCGSC and social welfare under a combination coordination contract are higher than both MR and M models, which indicates that a combination coordination contract optimizes the dual-channel green supply chain, increases the overall revenue of the supply chain, and improves social welfare.

\section{Numerical Examples}

In this section, we conduct a sensitivity analysis on numerical examples to verify the results and the usefulness of the four proposed models. The parameter values are set as $u=100, \alpha=0.4, k=5$, and $\mathrm{cm}=10$, and we focus on comparing the two following situations: $\beta=0.5, \lambda \in[0,1]$ and $\lambda=0.3, \beta \in[0,1]$. The effects of $\beta$ and $\lambda$ on the product green level, the profit of the manufacturer, the profit of the retailer, the profit of the DCGSC, and other equilibrium results in different models are shown in Figures 1-7.

Figures 1(a) and 1(b) demonstrate the effect of $\beta$ and $\lambda$ on the product green level; it can be seen that the product green level increases with an increase in the number of enterprises responsible CSR, $\beta$, and the coefficient of green preference, $\lambda$, in all decision models. This shows that an increase in consumers' green preference stimulates corporate green investment. Ultimately, the manufacturer invests more resources and capabilities to gain a competitive advantage by improving the product green level of its products. In addition, the product green level in the centralized model is equal to the product green level under the coordination of the combination contract, and it is easily seen that the product green level is higher in the centralized model than it is in the MR model, where the manufacturer solely bears the cost of CSR, which shows that the combination contract improves the product green level of the product. The product green level is the lowest when the manufacturer solely bears the cost of CSR. When the retailer and manufacturer share CSR costs, we find that the manufacturer would pay more toward improving the product green level. In the MRD model, the manufacturer determines the highest product green level. Therefore, we can elucidate that increased CSR and CGP lead to increased product green level. The combination contract will encourage the manufacturer to make more green investments.

Figure 2 demonstrates the effect of $\beta$ and $\lambda$ on online and offline selling prices. Figure 3 shows the effect of $\beta$ and $\lambda$ on the online and offline market demands. The three following results can be elucidated.

First, from Figure 2(a), it can be seen that online and offline selling prices decrease with an increase in $\beta$. and $\lambda$. This is attributable to the supply chain enterprises increasing their attention to consumer surplus value, which has the effect of reducing the price of green products. Therefore, we can conclude that increasing CSR reduces the price of green products. The offline selling price is the highest in the $\mathrm{M}$ model and the lowest in the centralized model. The online selling price is the highest in the centralized model and the lowest in the $\mathrm{M}$ model. This indicates that when the manufacturer solely bears the cost of CSR, it sets a high wholesale price, thereby increasing offline selling. However, the manufacturer and retailer share CSR costs, and the manufacturer sets a lower wholesale price to maintain stable long-term cooperation with the retailer; as a result, the retailer also sets a lower offline selling price. Notably, offline and online retail prices in the centralized model are equal to those of the MRD model; this means that the supply chain enterprises have forged a close relationship to set lower retail prices to pursue common goals.

Second, from Figure 3(a), it can be seen that the online market demand has shown an upward trend with the increase in $\beta$; recall that the online selling price and product green level increase with CSR, and the positive impact of product green level on market demand is greater than that of price. Therefore, online market demand is still showing an upward trend. However, the offline market demand gradually decreases with an increase in $\beta$ in the $\mathrm{M}$ model, and the offline market demand increases and then decreases with an increase in $\beta$ in the MR model.

Third, from Figures 2(b) and 3(b), we can see that the online and offline selling prices have shown an upward trend with the increase in $\lambda$, and online and offline sales have also shown an upward trend with the increase in $\lambda$, which 


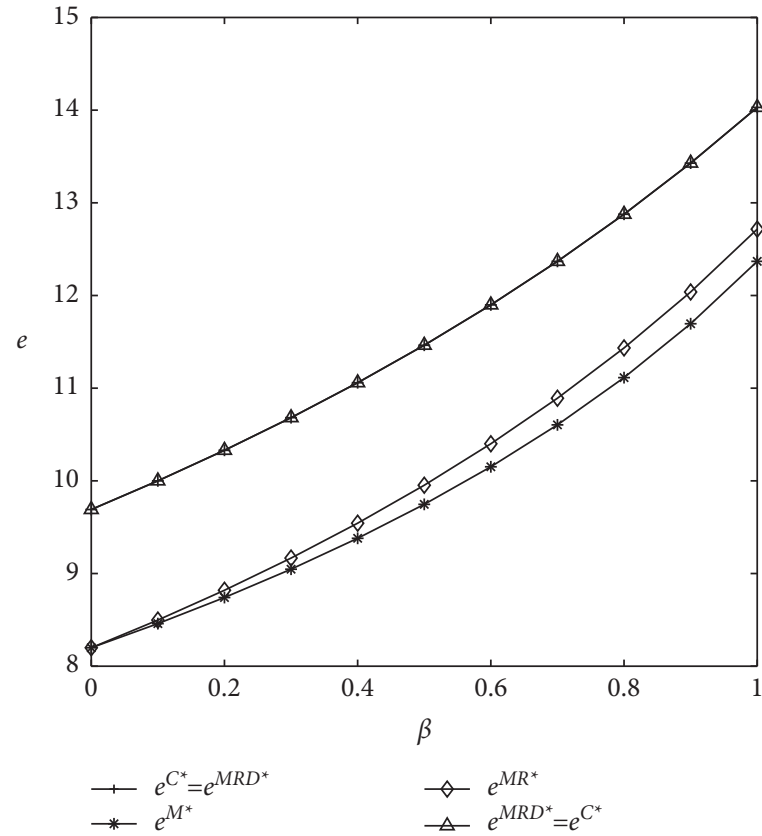

(a)

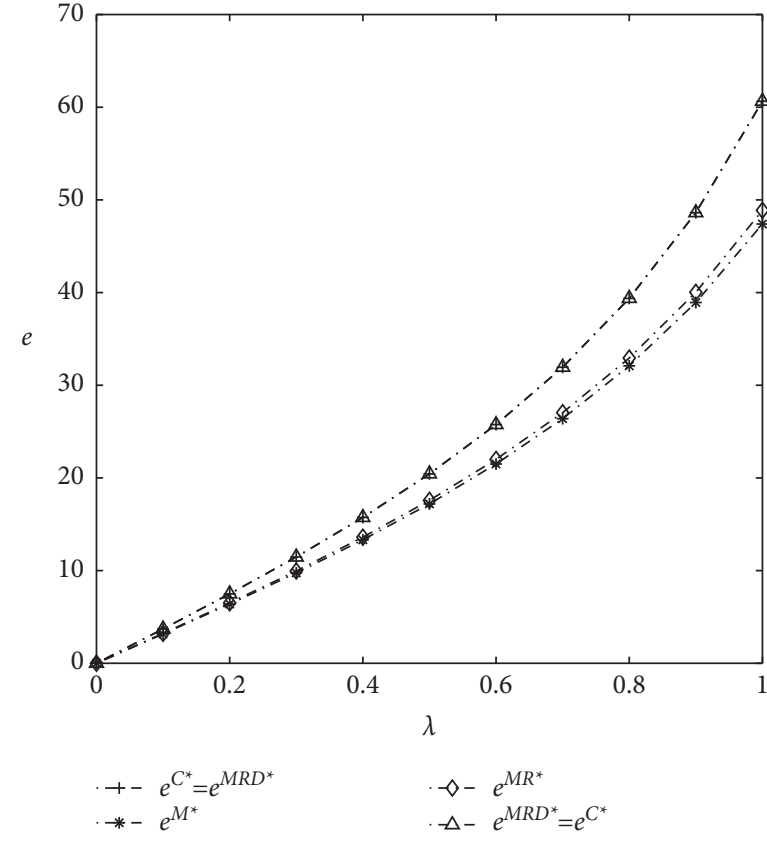

(b)

Figure 1: The effect of $\beta$ and $\lambda$ on the product green level.

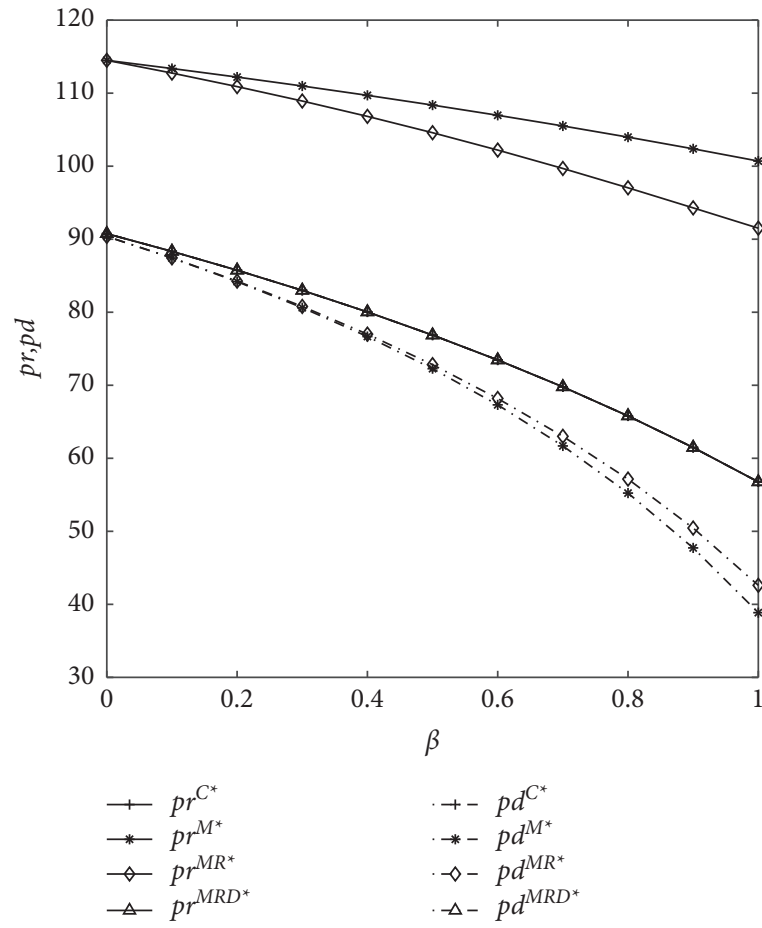

(a)

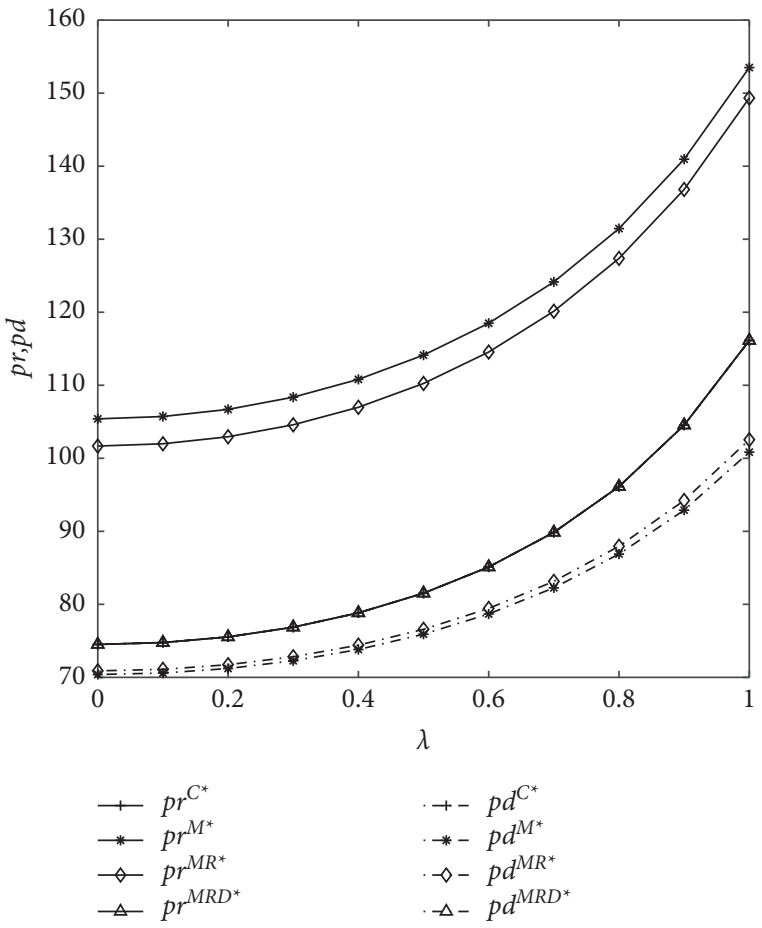

(b)

Figure 2: The effect of $\beta$ and $\lambda$ on online and offline selling price.

indicates that the CGP will stimulate the manufacturer to improve green technology of green products, so the increase in investment costs will increase the selling price of green products. However, the impact of product green level on consumer purchasing behavior is higher than that of price, which will cause market demand to increase with an increase in $\lambda$.

First, we see from Figures 4 and 5 that the profit of the manufacturer decreases with an increase in $\beta$. in the $M$ model, but there is a threshold $\beta=0.086$ that makes the 


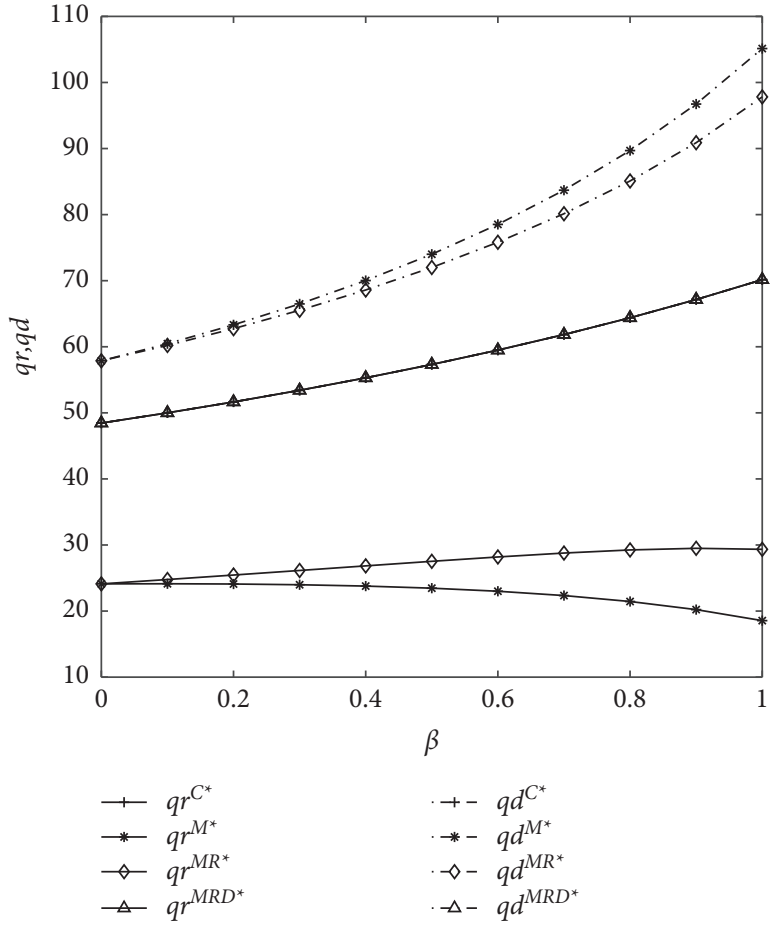

(a)

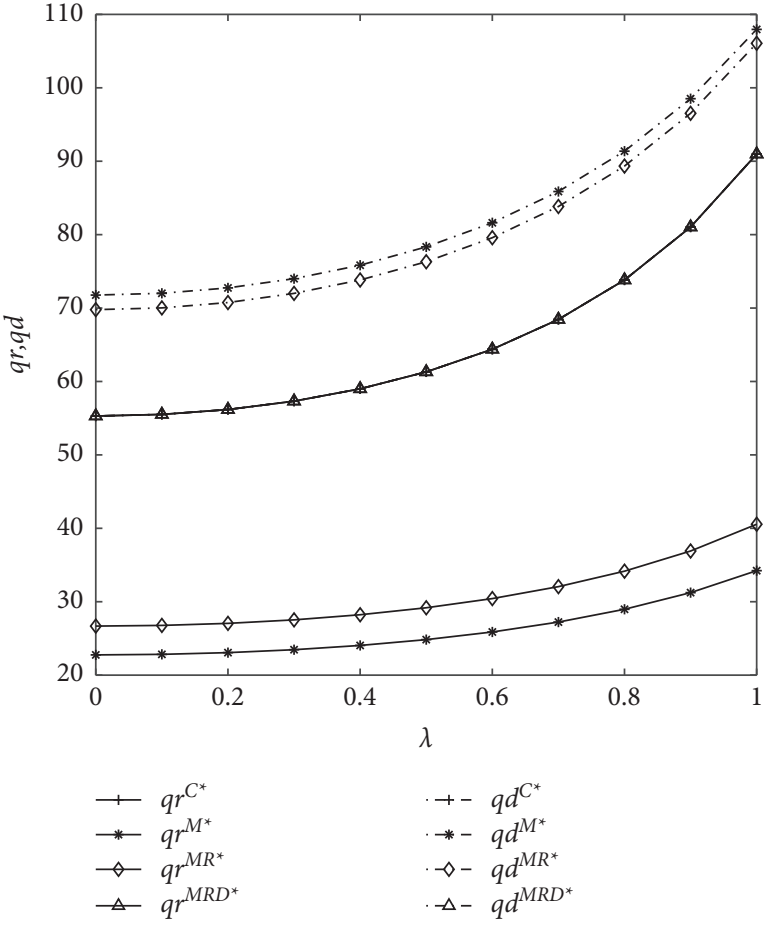

(b)

Figure 3: The effect of $\beta$ and $\lambda$ on online and offline channel demand.

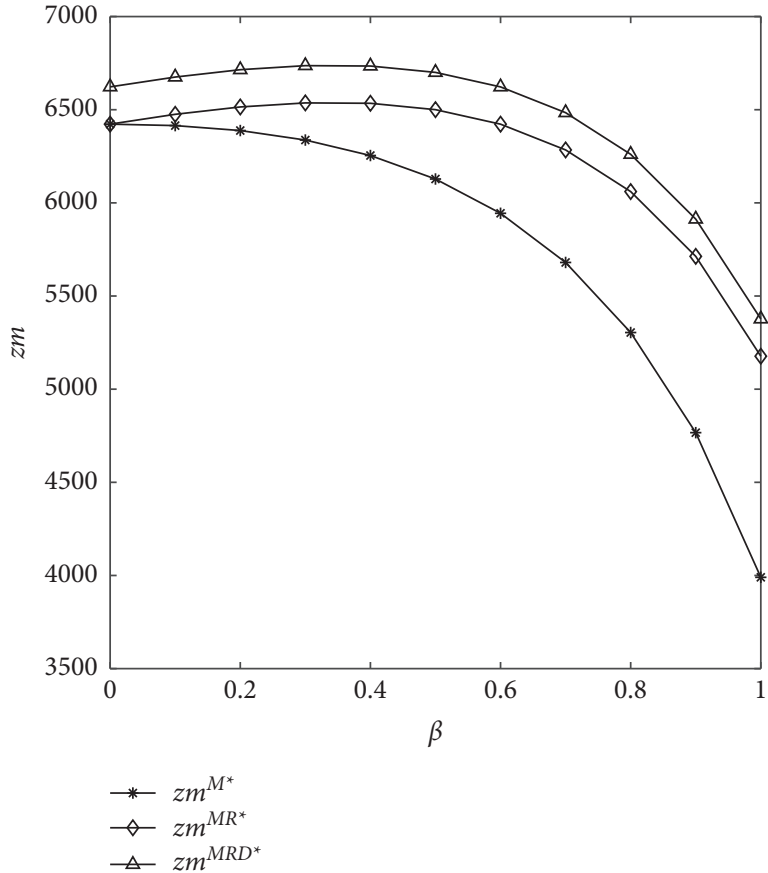

(a)

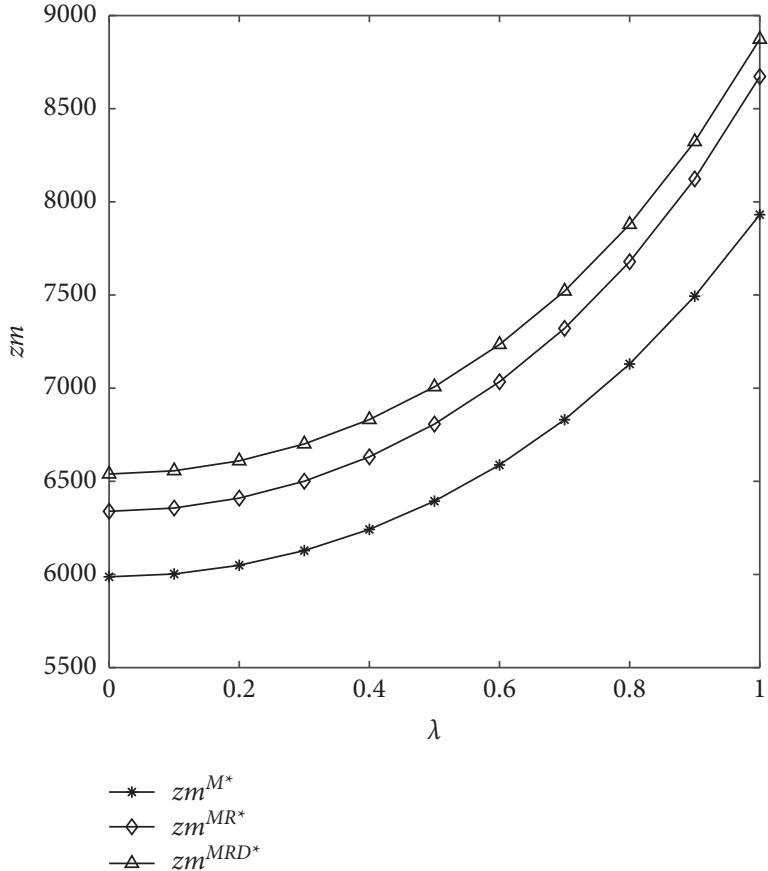

(b)

Figure 4: The effect of $\beta$ and $\lambda$ on the manufacturer's profit.

profit of the retailer first increase and then decrease. Second, there is a threshold $\beta=0.350$ that makes the profit of the manufacturer to first increase and then decrease with the increase of $\beta$, and the profit of the retailer shows a decreasing trend in the MR model. There is a threshold $\beta=0.086$ that makes the profit of the manufacturer first increase and then decrease with the increase of $\beta$ under the combination contract. When it is lower than the threshold $\beta=0.792$, the 


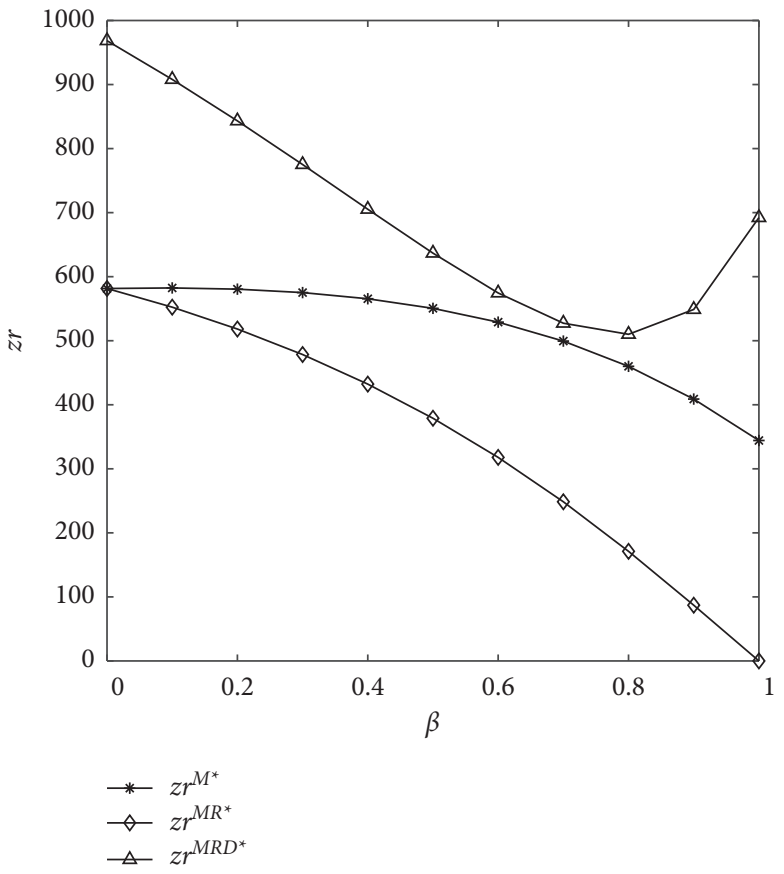

(a)

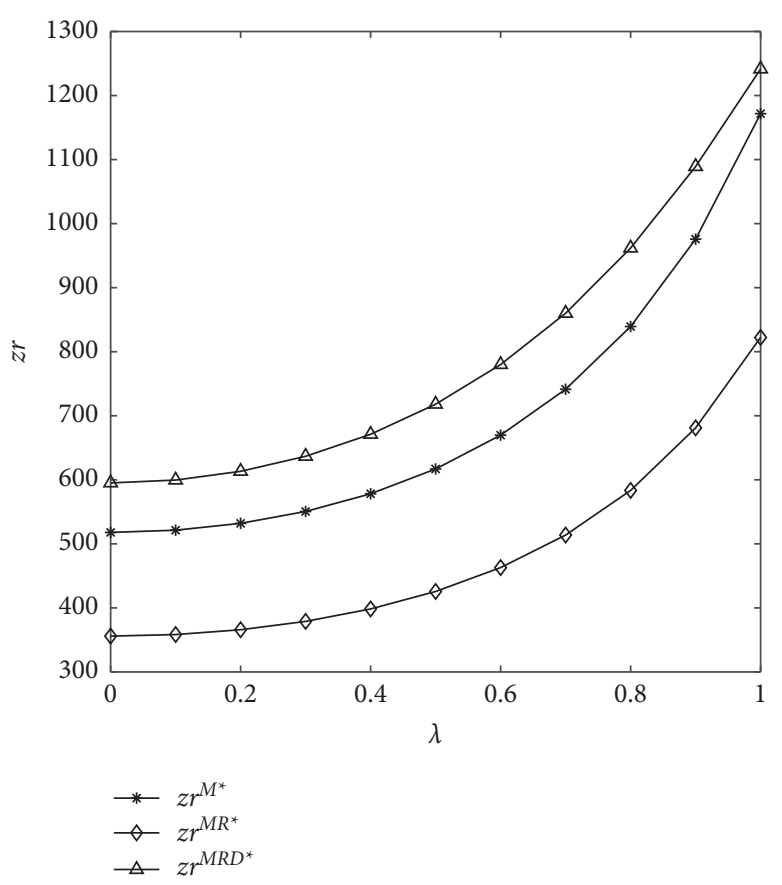

(b)

Figure 5: The effect of $\beta$ and $\lambda$ on the retailer's profit.

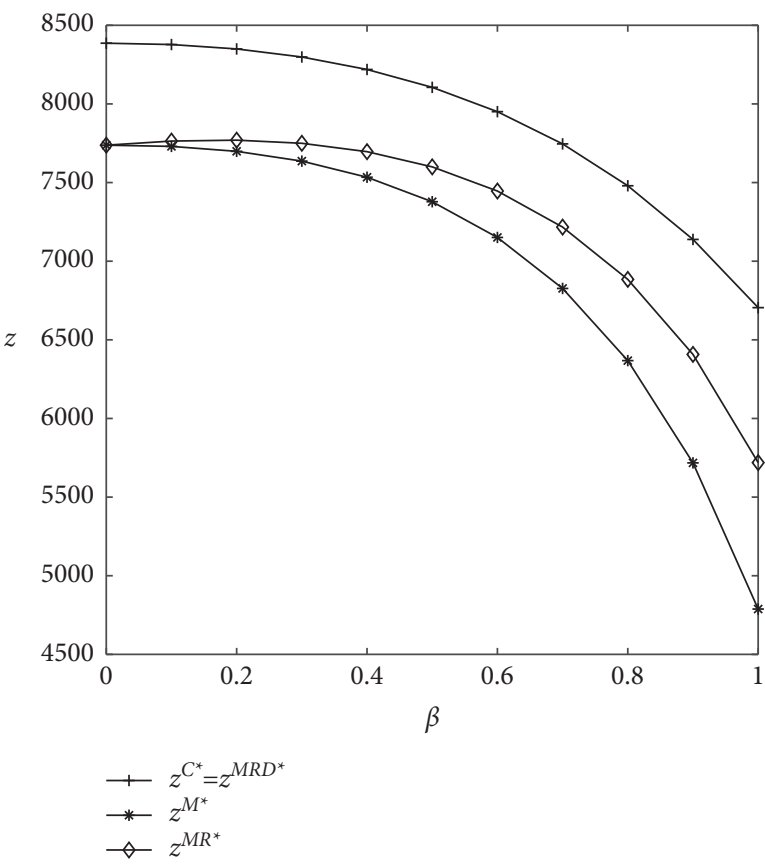

(a)

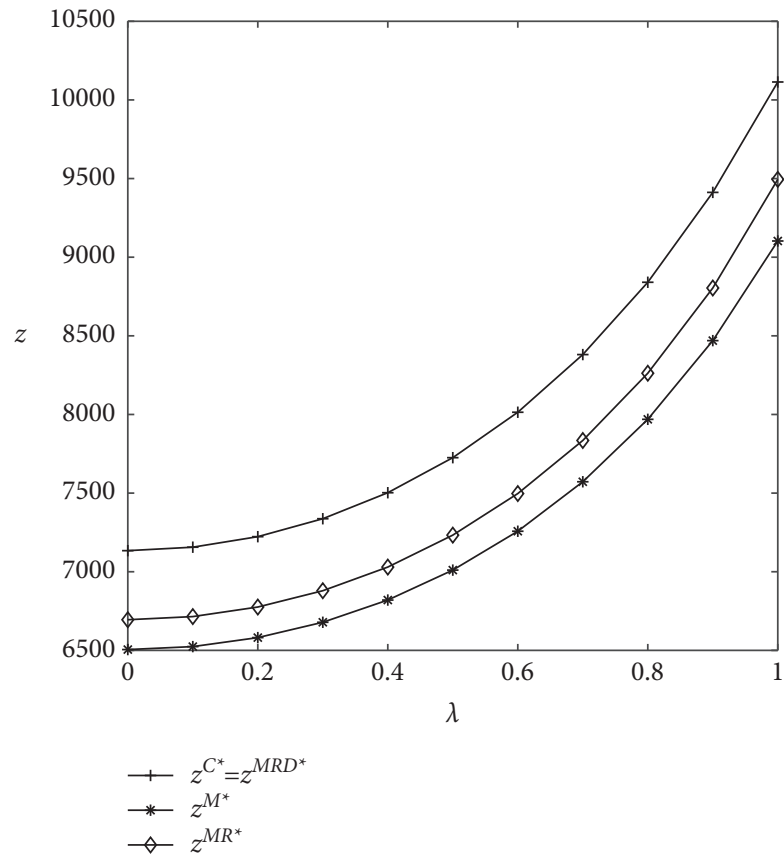

(b)

Figure 6: The effect of $\beta$ and $\lambda$ on the DCGSC profit.

retailer's profit decreases with the increase of $\beta$. When it is higher than the threshold 0.792 , the retailer's profit increases with $\beta$, which indicates that part of the online revenue shared by the manufacturer is higher than the CSR costs and franchise fee shared by the retailer.
Compared with other decision-making models, the manufacturer's profit is the lowest under the $\mathrm{M}$ model. The retailer's sharing of CSR costs is beneficial for the manufacturer to reduce CSR costs and gain more benefits, which will reduce the retailer's revenue. It is clear that a higher degree of CSR is 


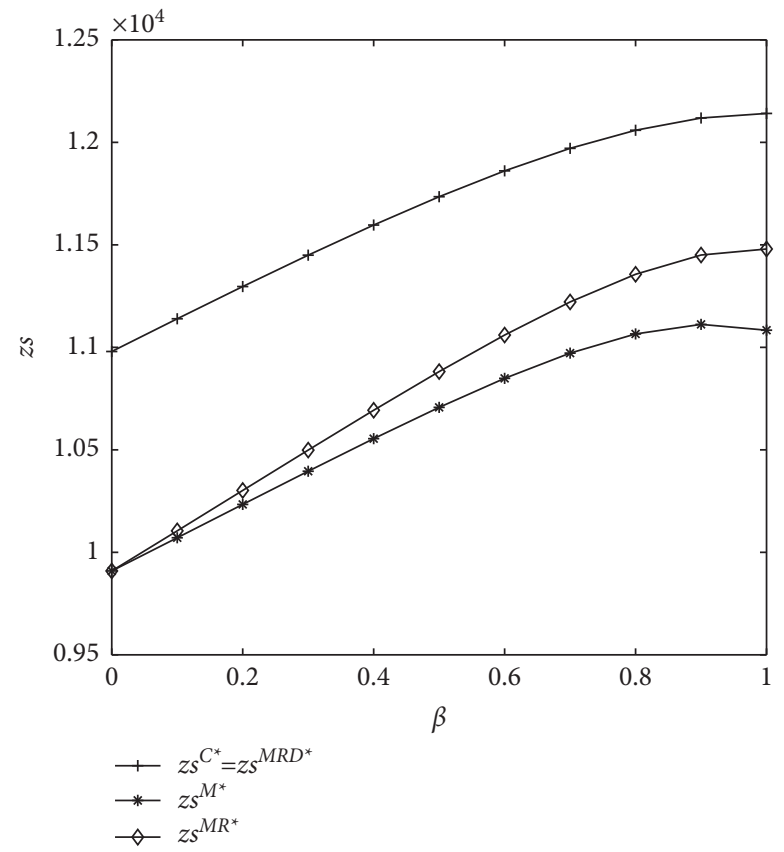

(a)

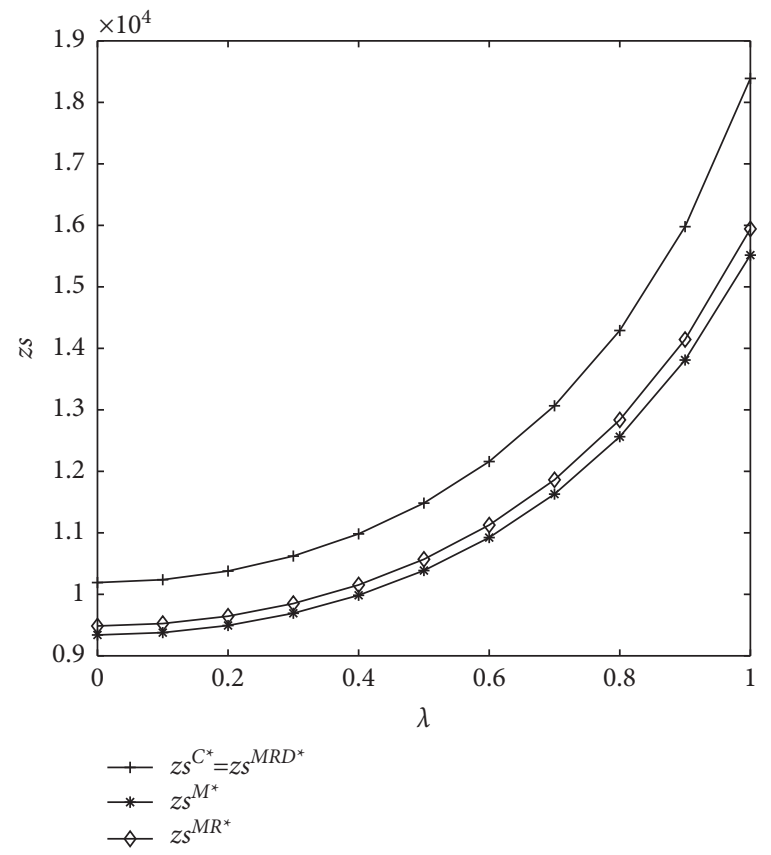

(b)

Figure 7: The effect of $\beta$ and $\lambda$ on social welfare.

not necessarily more beneficial to the manufacturer. The research results show that enhancing CSR within a reasonable range can increase the manufacturer's profits; however, exceeding a reasonable threshold will weaken the manufacturer's profit owing to the high CSR costs.

Thereafter, the combined contract can optimize the dualchannel supply chain and increase the profits of the dualchannel supply chain enterprises. This is because the manufacturer and the retailer have merged their interests through the contract mechanism, and ultimately both parties obtain a higher advantage.

Finally, the profits of the manufacturer and retailer increase with the increase in $\lambda$, which shows that enhancing consumers' green preference will prompt the manufacturer to pay more attention to improving the product green level, satisfying consumers' desire to purchase, and increase consumer purchases, thereby increasing the profits of both the manufacturer and retailer.

From Figures 6 and 7, we can see that the profits of the dual-channel supply chain show a decreasing trend with an increase in $\beta$. under the M and MRD models. This is because the increased benefits of one party of the dual-channel supply chain from enhancing CSR are lower than those of the other parties owing to the reduced costs of CSR. Under the MR decision model, there is a threshold $\beta=0.170$, which makes the overall profit of the DCGSC increase first and then decrease with parameter $\beta$. When the threshold is lower than $\beta=0.170$, the increase of the manufacturer's revenue is higher than the retailer's revenue decrease, which leads to an upward trend of the profit of the DCGSC. When the threshold is higher than 0.170 , the profits of both the manufacturer and the retailer decrease with parameter $\beta$, which leads to a decrease in the profits of the DCGSC. Under the M model, excessive CSR will reduce the profits of supply members, and social welfare will increase first and then decrease with parameter $\beta$. However, under the MR and MRD decision models, social welfare increases with parameter $\beta$. The revenue of the dual-channel supply chain under the $\mathrm{M}$ model is lower than the revenue under the MR model, indicating that the sharing of online CSR between the retailer and the manufacturer is beneficial to increase the revenue of the supply chain. The dual-channel supply chain revenue under the $\mathrm{C}$ and the MRD decision models is higher than the revenue of the M and MR models, indicating that the combined contract will optimize the DCGSC. With the increase in green preferences of consumers, the benefits of the DCGSC and social welfare are showing an upward trend, indicating that enhancing CGP is beneficial to the DCGSC and increasing social welfare.

\section{Conclusions}

In this study, to differ from the previous study (e.g., Li et al., 2018, Gang et al., 2020, Borin et al., 2013, and Wang and Hou, 2020), we constructed game models in four different situations (C Model, M Model, MR Model, and MRD Model). To better understand the impact of CSR and CGP on green behavior and the efficiency of the DCGSC, we also designed a combination contract to optimize the revenues of the supply chain and compared the equilibrium results under different circumstances and conducted a sample analysis to verify our results. Our findings differ from other studies in the following.

We concluded that CSR and CGP strongly influence the green supply chain. An increase in the degree of CSR and 
CGP can improve the product green level. This shows that the effective execution of CSR motivates manufacturers to invest more resources to improve green innovation technologies and capabilities and encourage their retailers to pay more attention to resource conservation and environmental protection in the marketing process. Therefore, for supply chain enterprises, to enhance their corporate reputation and influence, they should strengthen their involvement in CSR, expand their green innovation chain, and increase their supply of high-quality green products; in addition, the government can also enhance the awareness of CGP through publicity and education.

Our results indicated that enhancing CSR can reasonably control the selling prices in the DCGSC. Online market demand increases with an increase in CSR and CGP, but offline market demand shows different results in different decision-making models. In the $\mathrm{M}$ model, offline market demand gradually decreases with an increase in CSR. In the MR model, offline market demand increases first and then decreases with an increase in CSR. This shows that, with the enhancement of CSR in the supply chain, consumers have a higher preference for products with a high level of green innovation and low prices, and online market demand continues to increase. Therefore, the supply chain enterprises should cooperate in the execution and enhancement of CSR by raising their level of adherence to the requirements of pollution control and environmental protection, integrating CSR into their operations and management, manufacturing or selling high-quality green products at reasonable prices, and endeavoring to increase consumer surplus value and social welfare.

Our study has practical significance in that it can be used as decision support. The manufacturer can obtain more profits under the MR decision-making model than under the $\mathrm{M}$ model. Therefore, the situation where the manufacturer bears all the costs for CSR is not beneficial to the manufacturer and the long-term stability of the DCGSC. The longterm stability of DCGSC is safeguarded when both the manufacturer and the retailer share the cost of CSR. For the manufacturer, the intensity of CSR should not be as high as possible; instead, it should be controlled within a reasonable range. Enhancing supply chain CSR within a threshold increases the benefits to supply chain enterprises. When CSR exceeds the threshold (0.170), the cost of CSR will increase. Higher CSR costs will reduce the income of supply chain enterprises and affect the efficiency of the green supply chain. Enterprises in a supply chain must actively fulfill their responsibilities of environmental cogovernance and maintain the balance of their responsibilities in the supply chain.

Our study has great significance in that it can be used as a guide for corporate development. Supply chain enterprises fostering CSR and enhancing CGP help increase profit and social welfare. This paper designs a combination contract to increase the profits of both manufacturers and retailers and optimize the DCGSC, where the retailer's profit increases with $\beta$ when it is exceeds the threshold (0.792), in which the franchise fee depends on the coordination and negotiation capabilities of the supply chain enterprises. We also show that the establishment of a reasonable CSR distribution and contract mechanism is particularly important for supply chain enterprises to fulfill their CSR. Therefore, while taking into account the overall corporate CSR, enterprises in the supply chain must control their own CSR investment costs. Excessive CSR costs will reduce their benefits.

Our study could be further extended as follows: First, in characterizing the impact of CSR and CGP on innovation and supply chain efficiency, we could take government regulations into account to analyze their role in green innovation. For future research, it would be interesting and meaningful to consider the influence of these regulations. Second, we would focus on complex with multiple manufacturers and retailers. Third, for facilitating our research, we have limited our discussion to a single supply chain member in the model, and further studies could consider multiple supply chain members in the model. Thus, future research direction could consider the complexity of supply chains. It would be exploring how the government regulations of supply chain members affect their strategy choices.

\section{Appendix}

\section{Appendix A}

Proof of Proposition 5. in the C model, taking the first derivative of $e^{C *}$ with respect to $\beta$, we get $\partial e^{C *} / \partial \beta=2 \lambda k(\alpha-1)^{2}$ $(u-\mathrm{cm}+\alpha \mathrm{cm}) / \delta_{1}^{2}$.

Then, taking the first derivative of $\mathrm{pr}^{C *}$ with respect to $\beta$, we obtain

$\partial \mathrm{pr}^{C *} / \partial \beta=-2 k u(1-\alpha) / \delta_{1}-\left[\mathrm{ku}(\alpha \beta-\beta+1)-\mathrm{cm}\left(2 \lambda^{2}-\right.\right.$ $k+\alpha k)] / \delta_{1}^{2}$; and taking the first derivative of $e^{C *}$ with respect to $\lambda$, we get $\partial e^{C *} / \partial \lambda=2(u-\mathrm{cm}+\alpha \mathrm{cm}) / \delta_{1}+8 \lambda^{2}(u-$ $c m+\alpha c m) / \delta_{1}^{2}$. Recall that $k>2 \lambda^{2} /\left[2(1-\alpha)-(1-\alpha)^{2} \beta\right]$ and $\delta_{1}>0$, and we have $\partial e^{C *} / \partial \beta>0, \partial \mathrm{pr}^{C *} / \partial \beta<0, \partial \mathrm{pd}^{C *} / \partial \beta<0$, and $\partial e^{C *} / \partial \lambda>0$; other parameters are similar to the above proof; we can obtain that $\partial \mathrm{pd}^{j *} / \partial \beta>0, \partial \mathrm{pr}^{j *} / \partial \lambda>0$, $\partial \mathrm{pd}^{j *} / \partial \lambda>0, \partial \mathrm{cs}^{j *} / \partial \lambda>0, \partial z^{j *} / \partial \lambda>0$, and $\partial \mathrm{zs}^{j *} / \partial \lambda>0$.

Proof of Proposition 6. We now compare the product green level in different decision-making as follows: $e^{C *}-e^{M *}=$ $2 \lambda(u-\mathrm{cm}+\alpha \mathrm{cm})\left[1 / \delta_{1}-(\alpha-\beta-\alpha \beta+3) / A_{1}\right]$, where

$$
\begin{aligned}
A_{1}= & {\left[2 \lambda^{2}(\alpha \beta+\beta-\alpha-3)+\left(\alpha^{3}-\alpha^{2}-\alpha+1\right) \beta^{2}\right.} \\
& \left.-2 \beta\left(\alpha^{3}-\alpha^{2}-3 \alpha+3\right)+8-8 \alpha\right] k .
\end{aligned}
$$

Recall that $\delta_{1}>0$ and $A_{1}>0$. Thus, we have $e^{C *}-e^{M *}>0$; the proof is similar to the above and is thus omitted here; $e^{C *}-e^{\mathrm{MR} *}>0$ and $e^{M *}-e^{\mathrm{MR} *}<0$.

Proof of Proposition 7. We now compare the online selling price and the offline selling price, as well as online market demand and offline market demand, in different decisionmaking as follows: $\mathrm{pr}^{C *}-\mathrm{pr}^{M *}<0, \mathrm{pr}^{\mathrm{MR} *}-\mathrm{pr}^{M *}<0$, and $\mathrm{pr}^{\mathrm{MR} *}-\mathrm{pr}^{\mathrm{C} *}>0 ; \mathrm{pd}^{\mathrm{MR} *}-\mathrm{pd}^{\mathrm{M} *}>0, \mathrm{pd}^{\mathrm{C} *}-\mathrm{pd}^{\mathrm{MR} *}>0$, and $\mathrm{pd}^{C *}-\mathrm{pd}^{M *}>0 ; \mathrm{qr}^{C *}-\mathrm{qr}^{\mathrm{MR} *}>0, \mathrm{qr}^{\mathrm{MR} *}-\mathrm{qr}^{M *}>0$, and $\mathrm{qr}^{C *}-\mathrm{qr}^{M *}>0 ; \mathrm{qd}^{M *}-\mathrm{qd}^{\mathrm{MR} *}>0, \mathrm{qd}^{\mathrm{MR} *}-\mathrm{qd}^{C *}>0$, and 
$\mathrm{qd}^{M *}-\mathrm{qd}^{C *}>0$. The proof is similar to that of Proposition 6 and is thus omitted here.

Proof of Proposition 8. We now compare the manufacturers' profit and the retailers' profit in different decision-making as follows: $\quad \mathrm{zm}^{\mathrm{MR} *}-\mathrm{zm}^{M *}>0, \quad \mathrm{zm}^{\mathrm{MRD} *}-\mathrm{zm}^{M *}>0, \quad$ and $\mathrm{zm}^{\mathrm{MRD} *}-\mathrm{zm}^{M *}>0 ; \quad \mathrm{zr}^{\mathrm{MR} *}-\mathrm{zr}^{M *}<0, \quad \mathrm{zr}^{\mathrm{MRD} *}-\mathrm{zr}^{M *}>0$, and $\mathrm{zr}^{\mathrm{MRD} *}-\mathrm{zr}^{M *}>0$. The proof is similar to that of Proposition 6 and is thus omitted here.

Proof of Proposition 9. We now compare the profit of the DCGSC and social welfare in different decision-making as follows: $z^{\mathrm{MR}}-z^{M}>0 z^{\mathrm{MRD}}-z^{M}>0$, and $z^{\mathrm{MRD}}-z^{M}>0$; $\mathrm{zs}^{\mathrm{MR}}-\mathrm{zs}^{M}>0, \mathrm{zs}^{\mathrm{MRD}}-\mathrm{zs}^{M}>0$, and $\mathrm{zs}^{\mathrm{MRD}}-\mathrm{zs}^{M}>0$. The proof is similar to that of Proposition 6 and is thus omitted here.

\section{Data Availability}

The simulation data used are shown in the Numerical Examples section of the article.

\section{Conflicts of Interest}

The authors declare that they have no conflicts of interest.

\section{Acknowledgments}

This work was supported by Youth Research Fund of Beijing Wuzi University and Fund Project of Beijing Social Science (18GLA008).

\section{References}

[1] X. Wang and X. Chu, "A study of green technology innovation and financing contracts arrangement in manufacturing industry," Studies in Science of Science, vol. 37, pp. 351-361, 2019.

[2] C. W. Su, Y. Xie, S. Shahab, C. Faisal, M. Hefeez, and G. M. Qamri, “Towards achieving sustainable development: role of technology innovation, technology adoption and CO2 emission for BRICS," International Journal of Environmental Research and Public Health, vol. 18, no. 1, p. 227, 2021.

[3] M.-L. Tseng, Y.-H. Lin, K. Tan, R.-H. Chen, and Y.-H. Chen, "Using TODIM to evaluate green supply chain practices under uncertainty," Applied Mathematical Modelling, vol. 38, no. 11-12, pp. 2983-2995, 2014.

[4] I. None and S. K. Datta, "Pro-environmental concern influencing green buying: a study on Indian consumers," International Journal of Business and Management, vol. 6, pp. 124-133, 2011.

[5] J. Li, S.-Y. Pan, H. Kim, J. H. Linn, and P.-C. Chiang, "Building green supply chains in eco-industrial parks towards a green economy: barriers and strategies," Journal of Environmental Management, vol. 162, pp. 158-170, 2015.

[6] Y. He, C. Wen, and J. He, "The influence of China Environmental Protection Tax Law on firm performance - evidence from stock markets," Applied Economics Letters, vol. 27, pp. 1-4, 2019.

[7] B. Bisoyi and B. Das, "A paradigm shift: nano-sensory nudges stimulating consumer's purchase behaviour for green products driving towards environmental sustainability," Mater Today, 2021.

[8] G. Zhang, P. Cheng, H. Sun, Y. Shi, G. Zhang, and A. Kadiane, "Carbon reduction decisions under progressive carbon tax regulations: a new dual-channel supply chain network equilibrium model," Sustainable Production and Consumption, vol. 27, pp. 1077-1092, 2021.

[9] M. M. Parast, "An assessment of the impact of corporate social responsibility on organizational quality performance: empirical evidence from the petroleum industry," Operations Management Research, vol. 14, pp. 138-151, 2021.

[10] C. Clune and B. O’Dwyer, “Organizing dissonance through institutional work: the embedding of social and environmental accountability in an investment field," Accounting, Organizations and Society, vol. 85, Article ID 101130, 2020.

[11] M. Shahzad, Y. Qu, S. A. Javed, A. U. Rehman, and S. U. Rehman, "Relation of environment sustainability to CSR and green innovation: a case of Pakistani manufacturing industry," Journal of Cleaner Production, vol. 253, Article ID 119938, 2020.

[12] C. Tsendsuren, P. L. Yadav, S. H. Han, and H. Kim, "Influence of product market competition and managerial competency on corporate environmental responsibility: evidence from the US," Journal of Cleaner Production, vol. 304, 2021.

[13] D. Jamali and C. Karam, "Corporate social responsibility in developing countries as an emerging field of study," International Journal of Management Reviews, vol. 20, no. 1, pp. 32-61, 2018.

[14] W. Wu, Y. Liu, T. Chin, and W. Zhu, "Will green CSR enhance innovation? A perspective of public visibility and firm transparency," International Journal of Environmental Research and Public Health, vol. 15, no. 2, p. 268, 2018.

[15] J. Leng and Y. Gao, "Information disclosure quality of corporate social responsibility and innovation sustainability under financing constraints-data analysis based on small and medium-sized board enterprises," Science \& Technology Progress and Policy, vol. 36, pp. 77-84, 2019.

[16] J. Abbas, "Impact of total quality management on corporate green performance through the mediating role of corporate social responsibility," Journal of Cleaner Production, vol. 242, pp. 1-12, 2020.

[17] Y. Wang, J. Liu, X. P. Sui, and L. Liu, "Does corporate social responsibility improve financial performance? -evidence from pure green side," Finance Research Letters, vol. 36, 2020.

[18] M. Shahzad, Y. Qu, S. Ur Rehman, A. U. Zafar, X. Ding, and J. Abbas, "Impact of knowledge absorptive capacity on corporate sustainability with mediating role of CSR: analysis from the Asian context," Journal of Environmental Planning and Management, vol. 63, no. 2, pp. 148-174, 2020.

[19] W. Q. Li, X. P. Jia, Y. H. Liao, and Y. Liu, "An empirical research of the influence of corporate social responsibility (CSR) on firm's technological innovation performance with the integration of multiple perspectives," Chinese Journal of Management, vol. 15, pp. 237-245, 2018.

[20] G. Mehralian, J. A. Nazari, L. Zarei, and H. R. Rasekh, "The effects of corporate social responsibility on organizational performance in the Iranian pharmaceutical industry: the mediating role of TQM," Journal of Cleaner Production, vol. 135, pp. 689-698, 2016.

[21] S. Panda, N. M. Modak, and D. Pradhan, "Corporate social responsibility, channel coordination and profit division in a two-echelon supply chain," International Journal of Management Science and Engineering Management, vol. 11, no. 1, pp. 22-33, 2016. 
[22] T. Gang, J. Liu, G. Yu, Q. Wang, H. Sun, and H. Chen, "Multinational companies' coordination mechanism for extending corporate social responsibility to Chinese suppliers," Journal of Cleaner Production, vol. 267, 2020.

[23] S. Panda, N. M. Modak, and L. E. Cárdenas-Barrón, "Coordinating a socially responsible closed-loop supply chain with product recycling," International Journal of Production Economics, vol. 188, pp. 11-21, 2017.

[24] Y. Liu, B.-t. Quan, Q. Xu, and J. Y.-L. Forrest, "Corporate social responsibility and decision analysis in a supply chain through government subsidy," Journal of Cleaner Production, vol. 208, pp. 436-447, 2019.

[25] S. Panda, "Coordination of a socially responsible supply chain using revenue sharing contract," Transportation Research Part E: Logistics and Transportation Review, vol. 67, pp. 92-104, 2014.

[26] S. Swami and J. Shah, "Channel coordination in green supply chain management," Journal of the Operational Research Society, vol. 64, no. 3, pp. 336-351, 2013.

[27] X. Chen, X. Wang, and H. K. Chan, "Manufacturer and retailer coordination for environmental and economic competitiveness: a power perspective," Transportation Research Part E: Logistics and Transportation Review, vol. 97, pp. 268-281, 2017.

[28] J. Fan, X. Liang, and D. Ni, "A study on corporate social responsibility and product quality in supply chains under different channel power structures," Chinese Journal of Management, vol. 16, pp. 754-764, 2019.

[29] J. Jian, Y. Guo, L. Jiang, Y. An, and J. Su, “A multi-objective optimization model for green supply chain considering environmental benefits," Sustainability, vol. 11, no. 21, p. 5911, 2019.

[30] I. Papadopoulos, G. Karagouni, M. Trigkas, and E. Platogianni, "Green marketing," EuroMed Journal of Business, vol. 5, no. 2, pp. 166-190, 2010.

[31] N. Borin, J. Lindsey-Mullikin, and R. Krishnan, "An analysis of consumer reactions to green strategies," The Journal of Product and Brand Management, vol. 22, no. 2, pp. 118-128, 2013.

[32] P. Ma, C. Zhang, X. Hong, and H. Xu, "Pricing decisions for substitutable products with green manufacturing in a competitive supply chain," Journal of Cleaner Production, vol. 183, pp. 618-640, 2018.

[33] N. Mohd Suki, "Consumer environmental concern and green product purchase in Malaysia: structural effects of consumption values," Journal of Cleaner Production, vol. 132, pp. 204-214, 2016.

[34] M. E. Souri, F. Sajjadian, R. Sheikh, and S. S. Sana, "Grey SERVQUAL method to measure consumers' attitudes towards green products - a case study of Iranian consumers of LED bulbs," Journal of Cleaner Production, vol. 177, pp. 187-196, 2018.

[35] Y. Wang and G. Hou, "A duopoly game with heterogeneous green supply chains in optimal price and market stability with consumer green preference," Journal of Cleaner Production, vol. 255, Article ID 120161, 2020.

[36] Y. Yu, X. Han, and G. Hu, "Optimal production for manufacturers considering consumer environmental awareness and green subsidies," International Journal of Production Economics, vol. 182, pp. 397-408, 2016.

[37] G. Hua, S. Wang, and T. C. E. Cheng, "Price and lead time decisions in dual-channel supply chains," European Journal of Operational Research, vol. 205, pp. 13-126, 2010.
[38] A. A. Tsay and N. Agrawal, "channel conflict and coordination in the ecommerce age," Production and Operations Management, vol. 13, pp. 93-110, 2004.

[39] J. Cao and X. Zhang, "Coordination strategy of green supply chain under the free market mechanism," Energy Procedia, vol. 36, pp. 1130-1137, 2013.

[40] R. Zhang and B. Liu, "Group buying decisions of competing retailers with emergency procurement," Annals of Operations Research, vol. 257, no. 1-2, pp. 317-333, 2017.

[41] A. Ranjan and J. K. Jha, "Pricing and coordination strategies of a dual-channel supply chain considering green quality and sales effort," Journal of Cleaner Production, vol. 218, pp. 409-424, 2019.

[42] J. M. Van Loon-Steensma, H. A. Schelfhout, and P. Vellinga, "Green adaptation by innovative dike concepts along the Dutch Wadden Sea coast," Environmental Science \& Policy, vol. 44, pp. 108-125, 2014.

[43] Z. Basiri and J. Heydari, "A mathematical model for green supply chain coordination with substitutable products," Journal of Cleaner Production, vol. 145, pp. 232-249, 2017.

[44] T. Li, R. Zhang, S. Zhao, and B. Liu, "Low carbon strategy analysis under revenue-sharing and cost-sharing contracts," Journal of Cleaner Production, vol. 212, pp. 1462-1477, 2019.

[45] D. Ghosh and J. Shah, "Supply chain analysis under green sensitive consumer demand and cost sharing contract," International Journal of Production Economics, vol. 164, pp. 319-329, 2015.

[46] R. Dai, J. Zhang, and W. Tang, "Cartelization or Cost-sharing? Comparison of cooperation modes in a green supply chain," Journal of Cleaner Production, vol. 156, pp. 159-173, 2017.

[47] X. Pu, L. Gong, and X. Han, "Consumer free riding: coordinating sales effort in a dual-channel supply chain," Electronic Commerce Research and Applications, vol. 22, pp. 1-12, 2017.

[48] B. Davis-Sramek, R. Germain, and K. Krotov, "Examining the process $\mathrm{R} \& \mathrm{D}$ investment-performance chain in supply chain operations: the effect of centralization," International Journal of Production Economics, vol. 167, pp. 246-256, 2015.

[49] M. Asrar-ul-Haq, K. P. Kuchinke, and A. Iqbal, "The relationship between corporate social responsibility, job satisfaction, and organizational commitment: case of Pakistani higher education," Journal of Cleaner Production, vol. 142, pp. 2352-2363, 2017.

[50] Z. Liao, "Environmental policy instruments, environmental innovation and the reputation of enterprises," Journal of Cleaner Production, vol. 171, pp. 1111-1117, 2018.

[51] S. Panda, N. M. Modak, M. Basu, and S. K. Goyal, "Channel coordination and profit distribution in a social responsible three-layer supply chain," International Journal of Production Economics, vol. 168, pp. 224-233, 2015.

[52] M. Sinayi and M. Rasti-Barzoki, "A game theoretic approach for pricing, greening, and social welfare policies in A supply chain with government intervention," Journal of Cleaner Production, vol. 196, pp. 1443-1458, 2018. 